\title{
PERFIL EPIDEMIOLÓGICO DOS PACIENTES ATENDIDOS NAS CLÍNICAS DA DISCIPLINA DE CIRURGIA DA FACULDADE DE ODONTOLOGIA DE BAURU DA UNIVERSIDADE DE SÃO PAULO
}

\author{
Claudio Roberto Gaião Xavier
}

Dissertação apresentada à Faculdade de Odontologia de Bauru da Universidade de São Paulo, como parte dos requisitos para obtenção do título de Mestre em Odontologia, área de Estomatologia.

(Edição Revisada)

BAURU 


\title{
PERFIL EPIDEMIOLÓGICO DOS PACIENTES ATENDIDOS NAS CLÍNICAS DA DISCIPLINA DE CIRURGIA DA FACULDADE DE ODONTOLOGIA DE BAURU DA UNIVERSIDADE DE SÃO PAULO
}

\author{
Claudio Roberto Gaião Xavier
}

Dissertação apresentada à Faculdade de Odontologia de Bauru da Universidade de São Paulo, como parte dos requisitos para obtenção do título de Mestre em Odontologia, área de Estomatologia.

(Edição Revisada)

Orientador: Prof. Dr. Osny Ferreira Júnior

BAURU

2003 


\section{Xavier, Claudio Roberto Gaião}

X19p. Perfil epidemiológico dos pacientes atendidos nas clínicas da Disciplina de Cirurgia da Faculdade de Odontologia de Bauru da Universidade de São Paulo / Claudio Roberto Gaião Xavier - Bauru, 2003.

101p.:il. $30 \mathrm{~cm}$.

Dissertação (Mestrado) - Faculdade de Odontologia de Bauru. USP.

Orientador: Prof. Dr. Osny Ferreira Júnior

Autorizo, exclusivamente para fins acadêmicos e científicos, a reprodução total ou parcial desta dissertação/tese, por processos fotocopiadores e outros meios eletrônicos.

\section{Assinatura:}

Aprovação pelo Comitê de Ética em Pesquisa da FOB - USP.

Processo no 017/2003

Data: 31/03/2003 


\section{Claudio Roberto Gaião Xavier}

24 de março de 1976,

Pereira Barreto - SP

Filiação

$1994-1997$

$2001-2003$

Associações
Nascimento

Luiz Ferreira Xavier

Lourdes Gaião Xavier

Curso de Odontologia - Faculdade de Odontologia de Bauru, USP Bauru-SP.

Curso de Pós-Graduação em Odontologia, área de concentração em Estomatologia, em nível de Mestrado, na Faculdade de Odontologia de Bauru, USP.

SOBE - Sociedade Brasileira de Estomatologia

SBPqO - Sociedade Brasileira de Pesquisa Odontológica 
$\mathcal{N}$ a vida nos deparamos com diversos desafios:

Alguns ela mesma se encarrega de oferecer;

Tantos outros nos damos o direito de impô-los.

Ao superarmos estes desafios, sejam quais for, nos engrandecemos por superar os limites que pensávamos ter, e com coragem e aplicação, nos tornamos mais e mais fortes.

Apreciemos então cada lição, cada experiência, cada aprendizado que os caminhos destas conquistas nos proporcionam!

"O que importa de verdade na vida não são os objetivos que nos propomos, mas os caminhos que percorremos para consegui-los".

Peter Bamm 


\section{DEDICATÓRIA}

Aos meus pais Luiz e Lourdes,

Por fazerem de mim quem sou hoje e principalmente pelo empenho em ensinar a escolher e trilhar meus próprios caminhos. Por vezes abriram mão de seus desejos por minhas necessidades.

Aos meus irmãos Luiz e Marco,

Por todo apoio e estímulo e por toda confiança que em mim depositaram. Ajudaram-me mais do que podem supor!

Mesmo que tentasse, não encontraria palavras que expressassem o que sinto por tudo o que vocês me deram e proporcionaram. 


\section{AGRADECIMENTOS ESPECIAIS}

\section{Ao Prof. Dr. Osny Ferreira Júnior}

Amigo que acompanhou meus primeiros passos na odontologia, orientando minha formação, quando mesmo sem saber foi exemplo de caráter e integridade.

Acabou por aceitar a conturbada tarefa de assumir minha orientação quando já decorrida parte do meu curso de mestrado, encarando este desafio com competência e dinamismo.

Terei sempre muita admiração e respeito por você.

Que nossa convivência se prolongue por muito tempo.

Muito obrigado! 


\section{À Aline,}

Por estar ao meu lado durante a realização deste trabalho, acompanhando-me em um sonho. Ofereceu sempre ajuda, compreensão e carinho. Foi sempre fonte de alegrias e exemplo de determinação.

Muito obrigado! 


\section{AGRADECIMENTOS}

À Faculdade de Odontologia de Bauru da Universidade de São Paulo, na pessoa de sua Diretora Profa. Dra. Maria Fidela de Lima Navarro.

À Comissão de Pós-Graduação da Faculdade de Odontologia de Bauru, na pessoa de seu Presidente, Prof. Dr. José Carlos Pereira.

Aos professores das Disciplinas de Estomatologia e Radiologia da Faculdade de Odontologia de Bauru, Prof. Dr. José Humberto Damante, Profa. Dra. Ana Lúcia Álvares Capelozza, Prof. Dr. Luiz Eduardo Montenegro Chinellato e Profa. Dra. Izabel Regina Fisher Rubira, que foram fonte constante de conhecimento e exemplos de paixão pela arte de ensinar. Que eu consiga ser um propagador destes conhecimentos e reflexo deste exemplo de conduta acadêmica.

Ao Prof. Dr. Eduardo Sant'Ana, pelas oportunidades de aprendizado, pelo incentivo durante toda a graduação e por me 
acolher, quando recém-formado, durante estágio na Disciplina de Cirurgia.

Aos funcionários das Disciplinas de Estomatologia, Radiologia e Cirurgia, Camila, Fernanda, Josiele, Marilia, José Messias e Walderez, pela presteza e disposição em sempre ajudar e pelos momentos de descontração compartilhados. Certamente ensinaram muito mais do que podem supor.

Aos companheiros do curso de Mestrado, Fernando, Flávio, Luis Fernando, Josiane e Nicole, por tudo o que passamos juntos. Cada um, ao seu modo, trouxe uma lição que sempre será lembrada.

Às amigas Ana Lúcia, Viviane e Roberta, por todo carinho e atenção dispensados em vários momentos, além de toda confiança em mim depositada.

A todos os funcionários do Serviço de Biblioteca e Documentação da Faculdade de Odontologia de Bauru-USP, por toda a ajuda, sempre prestada com paciência e cordialidade.

À CAPES, pelo apoio financeiro durante o curso de Mestrado. 


\section{SUMÁRIO}

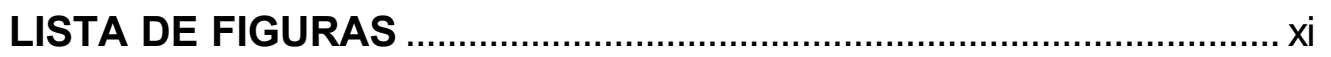

LISTA DE TABELAS ……...............................................................

LISTA DE ABREVIATURAS ………………………......................

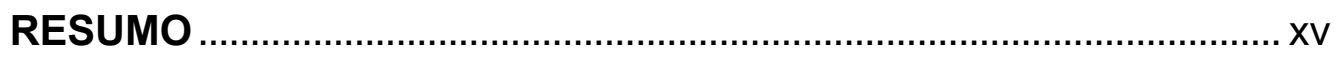

1 INTRODUÇÃO

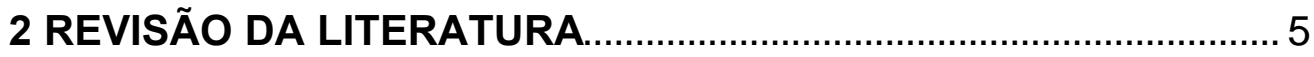

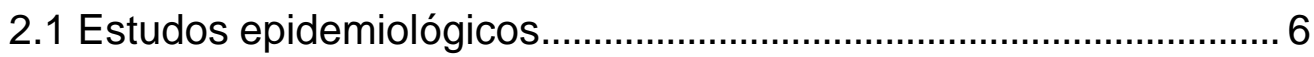

2.2 Importância das alterações e condições sistêmicas e do exame clínico 12

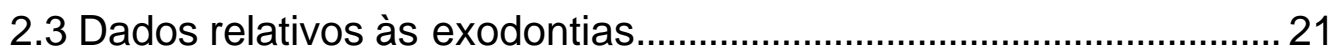

2.3.1 Causas determinantes de exodontias............................................. 22

2.3.2 Dados epidemiológicos relativos às exodontias ............................ 25

2.3.3 Dados relativos aos terceiros molares............................................. 34

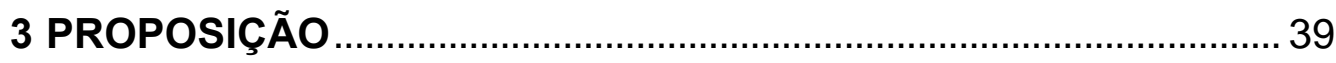

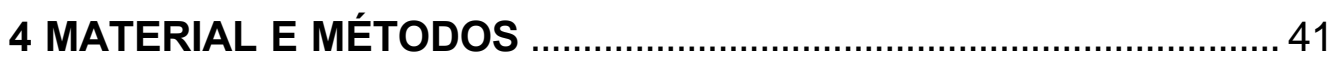

5 RESULTADOS

6 DISCUSSÃO

6.1 Gênero, idade e procedência dos pacientes.................................... 66

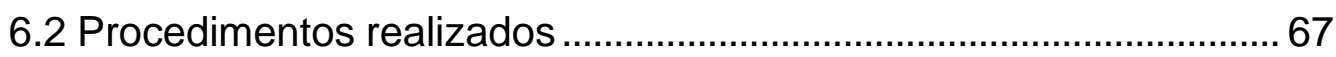

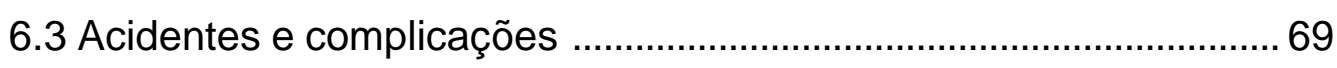

6.4 Exame clínico e história médica......................................................... 71

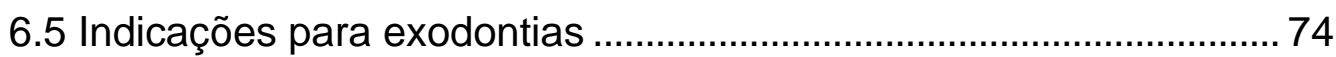

6.6 Posição dos terceiros molares …………………………………....... 77

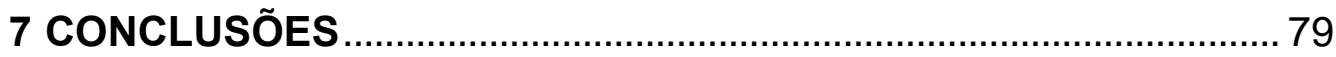

ANEXOS

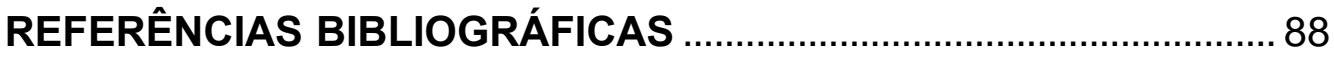

ABSTRACT

APÊNDICES 


\section{Lista de figuras}

FIGURA 1 Classificação da posição dos terceiros molares segundo PELL; GREGORI ${ }^{50}$

FIGURA 2 Classificação da posição dos terceiros molares segundo WINTER ${ }^{69}$

FIGURA 3 Exemplo de dente com indicação para exodontia por cárie

FIGURA 4 Exemplo de dente com indicação para exodontia por doença periodontal

FIGURA 5 Exemplo de dente com indicação para exodontia por traumatismo dentário

FIGURA 6 Exemplo de dente não irrompido com indicação para exodontia

FIGURA 7 Exemplo de dente supranumerário com indicação para exodontia

FIGURA 8 Exemplo de dente decíduo persistente com indicação para exodontia

FIGURA 9 Exemplo de dente com indicação para exodontia por perfuração endodôntica

FIGURA 10 Tela do programa Microsoft Excel no momento da aplicação de filtro para análise dos dados

FIGURA 11 Distribuição percentual dos pacientes atendidos nas clínicas da Disciplina de Cirurgia, segundo o gênero, no período de 1997 a 2002

FIGURA 12 Distribuição dos pacientes atendidos de acordo com faixa etária

FIGURA 13 Distribuição percentual da procedência das radiografias. 54

FIGURA 14 Distribuição percentual de causas de hemorragias ........ 58

FIGURA 15 Distribuição percentual das causas de alergia ............... 58 
FIGURA 16 Distribuição percentual de pacientes diabéticos ou com histórico familiar

FIGURA 17 Distribuição percentual dos vícios, hábitos ou manias relatados

FIGURA 18 Distribuição percentual entre respostas afirmativas e negativas a respeito de alterações cardiovasculares em pacientes hipertensos 60 


\section{Lista de tabelas}

TABELA 1 Municípios com maior número de pacientes atendidos 53

TABELA 2 Número de indivíduos atendidos por região de BauruSP.

TABELA 3 Freqüência dos procedimentos realizados nas clínicas da disciplina de Cirurgia da FOB-USP, por tipo........... 55

TABELA 4 Prevalência de acidentes e complicações..................... 56

TABELA 5 Distribuição numérica de respostas afirmativas, segundo tipo de alteração de saúde........................... 57

TABELA 6 Prevalência das indicações para exodontia dos dentes decíduos......................................................... 61

TABELA 7 Prevalência das indicações para exodontia dos dentes permanentes............................................... 61

TABELA 8 Distribuição das indicações de exodontia por faixas

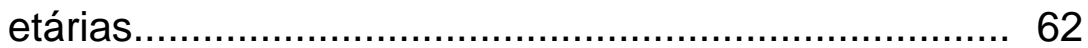

TABELA 9 Distribuição dos terceiros molares segundo classificação de PELL; GREGORY ${ }^{50}$............................6 63

TABELA 10 Distribuição dos terceiros molares segundo classificação de WINTER ${ }^{69}$ 


\section{Lista de abreviaturas e símbolos}

AHCPR - Agency for Health Care Policy and Research

BBO - Bibliografia Brasileira de Odontologia

CPO-D - Dente(s) permanente(s) cariado(s), perdido(s) e obturado(s)

DPP - Dente(s) potencialmente perdido(s)

FOB - Faculdade de Odontologia de Bauru

$\mathrm{Hg}$ - Mercúrio

JNC - Joint National Committee

LILACS - Literatura Latino-Americana e do Caribe em Ciências da Saúde

MEDLINE - Medlars Online

mm - milímetros

OMAR - Office Medical Aplications and Research

OMS - Organização Mundial da Saúde

UNICAMP - Universidade Estadual de Campinas

USP - Universidade de São Paulo 


\section{Resumo}

Este estudo analisou os prontuários dos pacientes recebidos pelas clínicas da Disciplina de Cirurgia da Faculdade de Odontologia de Bauru-USP, entre janeiro de 1997 e dezembro de 2002. Os dados relativos ao gênero, idade, procedência, tipo de procedimento realizado, data da execução do procedimento, número de dentes extraídos, acidentes e complicações ocorridas, informações da história médica colhidas na anamnese, pressão arterial, procedência da radiografia utilizada no planejamento das cirurgias $e$ as indicações para as exodontias foram anotados. A análise dos dados obtidos permitiu as seguintes constatações: (1) foram atendidos no período analisado 3927 pacientes; (2) $59,2 \%$ dos pacientes possuíam idade entre 11 e 30 anos; (3) 67,39\% dos pacientes realizaram exame radiográfico na própria FOB-USP; (4) a alveolite foi a complicação mais observada; (5) as prevalências de diabetes e hipertensão arterial foram de $2,32 \%$ e $18,53 \%$, respectivamente; (6) foram extraídos 8471 dentes de 2359 pacientes, com média de 3,59 dentes extraídos por paciente. A partir dos dados obtidos pode-se concluir que: (1) houve maior procura pelas clínicas da Disciplina de Cirurgia da FOB - USP por pacientes do gênero feminino; (2) a maior freqüência de indivíduos, segundo as faixas etárias, foi para os pacientes entre 21 e 30 anos; (3) uma filosofia conservadora em relação às indicações de exodontia deve prevalecer, tendo em vista que a freqüência de indivíduos atendidos com idade inferior a 30 anos foi de 59,9\%; (3) Bauru foi o município mais beneficiado pelos serviços das clínicas da Disciplina de Cirurgia da FOB-USP; (4) o procedimento mais realizado foi a exodontia; (5) os índices de acidentes e complicações observados estão em níveis plenamente satisfatórios; (6) a cárie e suas consequêencias não são a principal causa de atendimento nas clínicas da

Disciplina de Cirurgia da FOB-USP, sendo a principal indicação para exodontia os dentes não irrompidos. 
1 INTRODUÇÃO 


\section{Introdução}

Estudos epidemiológicos revelam informações que permitem avaliar o passado e tentar prever cenários futuros ${ }^{4,19,46,54}$. São utilizados para estudos de situação de saúde, vigilância epidemiológica, estudos "causais", e avaliação de serviços, programas e tecnologias relativas à saúde. Particularmente, os estudos de investigação causal têm demonstrado relevância em pesquisas de natureza clínica, principalmente no meio universitário, onde alcançam certa cientificidade ${ }^{19}$.

Segundo SAMAJA ${ }^{60}$, o principal pressuposto de toda investigação científica é que o objeto de estudo seja inteligível. Esta inteligibilidade depende da descrição do objeto, que visa identificar os componentes e caracterizá-los, e da possibilidade de reelaboração conforme um padrão de assimilação compatível com a razão humana. É, portanto, na descrição do objeto que se encontra o passo inicial na elaboração de raciocínios, idéias e hipóteses. Para poder descrever de maneira científica a realidade é preciso explicitar de que modo é feita a sua fragmentação, segundo determinadas categorias. As proposições descritivas têm como valores conceitos classificatórios, conceitos comparativos, conceitos métricos e outros.

$\mathrm{Na}$ epidemiologia, um passo essencial para o estudo de uma doença é descrever precisamente sua ocorrência na população. Essa descrição tem como categorias básicas a distribuição temporal, a distribuição espacial e a distribuição segundo atributos pessoais, visando a identificar o padrão geral de ocorrência e os grupos de risco. A descrição metódica do comportamento da doença permite a elaboração de hipóteses causais com base na ocorrência usual de doenças conhecidas e possibilita o uso da analogia tanto no estudo das doenças novas quanto na explicação de doenças anteriormente conhecidas ${ }^{4,54}$. 
Sobre a condição de saúde geral do paciente, o conhecimento de alterações sistêmicas concomitantes é de grande valia na área odontológica, uma vez que diversas doenças poderão influenciar a indicação de um determinado procedimento ou modificar o plano de tratamento em diferentes instâncias 11,26,30,62. Portanto, estudos descritivos podem contribuir na determinação de um padrão epidemiológico para uma população alvo, atribuindo certa previsibilidade nas alterações a serem encontradas nos indivíduos constituintes desta população. Podem ainda fornecer subsídios para explicação de alterações encontradas, permitindo estudos elucidativos quanto à associação de situações e alterações de saúde ${ }^{11,62}$.

Do ponto de vista da atenção ao paciente, a odontologia sofreu uma mudança em seu perfil, inicialmente restaurador e curativo, adotando também um caráter preventivo que abrange todas as suas especialidades ${ }^{21}$. LEAVELL e CLARK ${ }^{29}$ propuseram cinco níveis de prevenção, sendo eles: promoção da saúde; proteção específica; diagnóstico precoce com tratamento imediato; limitação do dano; e reabilitação. Desta forma, a prevenção da perda dentária inicia-se em fases onde ainda não houve danos propriamente ditos, pelo uso de flúor, adequação de hábitos alimentares e de higienização, ou em fases mais avançadas, pela instituição de procedimentos curativos adequados, como nos tratamentos endodônticos, periodontais e dentisteria. Observa-se então que, frente à instituição destes procedimentos preventivos e ao desenvolvimento de técnicas modernas visando a recuperação e manutenção de dentes danificados, houve nos últimos anos um decréscimo no número de dentes perdidos na população 21,36 .

No entanto, a exodontia que ocupa o quarto e quinto níveis de prevenção acima citados, ainda se faz necessária em vários casos e por diversos motivos $5,12,21,36,53$. São necessários sólidos conhecimentos para que haja a indicação correta da extração de um dente, para que não se 
incorra em perda dentária desnecessária, levando à mutilação do paciente por perda de um órgão passível de recuperação. Apenas quando findadas as possibilidades de cura do dente em questão é que se deve optar pela extração do mesmo, ou ainda quando tal exodontia for parte de um plano de tratamento, ortodôntico ou protético, devidamente fundamentado e objetivando o adequado restabelecimento funcional e/ou estético da condição bucal do paciente ${ }^{21,36,53}$. Observa-se também que a literatura odontológica acerca das causas determinantes de exodontias é vasta, tanto em âmbito nacional 5,21,22,23,36,41 quanto internacional $7,10,15,24,37,42,43,45,47,48,55,70$. Em contrapartida, estudos para a determinação do perfil epidemiológico de pacientes atendidos por um determinado serviço ou residentes numa região têm sido pouco praticados ${ }^{12,41}$.

Justifica-se desta forma a realização de estudos que tracem o perfil epidemiológico dos pacientes em diferentes serviços de saúde, além da incidência de diferentes alterações sistêmicas ou locais, fornecendo dados importantes para futuras comparações e avaliações, embasando pesquisas mais aprofundadas acerca de diversos temas e divulgando para a comunidade científica informações que suscitem novos questionamentos ou elucidem antigos. 


\section{REVISÃO DA LITERATURA}




\section{Revisão da literatura}

\subsection{Estudos epidemiológicos}

Discutindo a epidemiologia relacionada aos serviços de saúde, GOLDBAUM $^{19}, 1996$, reafirmou a importância da epidemiologia na produção de conhecimento, principalmente em relação ao quadro de prioridades sanitárias, após contribuir com o estudo das doenças infecto-contagiosas, demonstrando grande capacidade para avaliar a ocorrência e distribuição das doenças crônicas, e mais recentemente sendo incorporada a áreas como a genética e a medicina molecular. Após experimentar notável evolução tecnológica, a epidemiologia permitiu estabelecer associação entre fatores lesivos e ocorrência de doenças, como por exemplo, o caráter nocivo do tabaco na promoção de doenças, o conceito de estilo de vida associado ao maior ou menor risco de desenvolvimento de doenças, e também evidências para os efeitos protetores, como o uso do flúor na prevenção de cáries e a relação entre vacinas e sua eficácia. $O$ autor se utilizou da definição de epidemiologia formulada por ROUQUAYROL ${ }^{57}, 1993$, como sendo a "ciência que estuda o processo saúde-doença em coletividades humanas, analisando a distribuição e os fatores determinantes das enfermidades, danos à saúde e eventos associados à saúde coletiva, propondo medidas específicas de prevenção, controle, ou erradicação de doenças, e fornecendo indicadores que sirvam de suporte ao planejamento, administração e avaliação das ações de saúde". É possível destacar quatro usos primários da epidemiologia pelos serviços de saúde: nos estudos de situação de saúde; na vigilância epidemiológica; nos estudos "causais"; e na avaliação de serviços, programas e tecnologias. Apesar do desenvolvimento experimentado pela epidemiologia, ela ainda permanecia subvalorizada e subaproveitada pelos setores de saúde 
pública. Argumenta ainda que a transferência de conhecimento não obedece a uma lógica linear, atendendo geralmente necessidades mediadas por motivos sociais, políticos ou econômicos, e apesar do discurso adotado pelo setor de saúde, o uso da epidemiologia não é considerado em sua plenitude. Retomando os usos da epidemiologia, em particular o de estudos de investigação causal, observou-se que mesmo não atendendo a contento a difusão merecida, e por isso ainda subaproveitado e merecedor de maior atenção, nos centros universitários estes estudos têm alcançado certa cientificidade, sendo muito utilizado em pesquisas de natureza clínica. A epidemiologia na realização de investigação causal, juntamente com a avaliação de serviços, é notadamente mais empregada que nos estudos da situação de saúde e na vigilância epidemiológica.

Ao discutir a utilização da epidemiologia como meio de avaliação de serviços de saúde, NOVAES ${ }^{46}$, 1996, afirma que a interação entre as informações obtidas na clínica e utilizadas em dimensão coletiva pela epidemiologia torna-se uma fonte fundamental de dados para tais avaliações. Contudo nem sempre as informações obtidas condizem com o esperado, demonstrando forte influência da variabilidade, e em estudos onde se parte de um conhecimento tido como invariante terminam por evidenciar discordâncias com os pressupostos que o embasavam. Tal afirmação não é feita com base no problema de saúde em si, mas sim nos meios de produção de conhecimento sobre as doenças. As áreas atuantes nos serviços de saúde que se utilizam deste como fonte de produção de conhecimento são a clínica, epidemiologia, administração e planejamento, cada qual com seu ponto de vista e modo de atuação dentro deste complexo: a clínica busca incessantemente o controle sobre a doença; a epidemiologia, que por meio de métodos cada vez mais sofisticados busca identificar a causa verdadeira da doença ou agravos; e a administração e planejamento, que buscam a instituição de ordem, por meio de ações e métodos que não se opõem ao 
caráter de "ações racionais em busca de um fim". E é justamente nesta incongruência que está a dificuldade de unificação do universo da construção de conhecimento em serviços de saúde. A necessidade de uma nova óptica a respeito da unificação destas áreas na captação, estudo e manuseio das informações no serviço de saúde pública é notada pelo movimento em instituições de financiamento de pesquisas, mais evidenciada em países onde este setor se encontra mais estruturado. No Brasil, o compromisso econômico e social com a atenção em saúde pública encontra-se incompleto. O autor ressaltou a criação de entidades de fomento especificamente direcionadas para este setor, como o National Institue of Health Services Research, em 1968, a Office Medical Aplications and Research (OMAR), em 1977, e a Agency for Health Care Policy and Research (AHCPR), em 1989, embuídas da obrigação de financiar e gerenciar a aquisição de novos conhecimentos e utilização dos já existentes a respeito do tema, e tidas por muitos autores como fundamentais para o desenvolvimento de um serviço de saúde pública mais completo e produtivo, social e cientificamente. Esta opinião não é unânime visto que alguns epidemiologistas afirmam que apesar de tais entidades terem sido responsáveis pelo investimento de 200 milhões de dólares, em cinco anos de pesquisas, ainda não se chegou ao conhecimento verdadeiro de algumas doenças, e que o próprio prontuário médico geralmente não é o meio ideal de se obter informações. Mas mesmo para esta corrente de epidemiologistas é inegável que nas condições atuais dificilmente será possível estudar todos os procedimentos e tecnologias na área de saúde, e ainda mais difícil para a epidemiologia será conhecer com veracidade a incidência, a prevalência e a mortalidade de grande parte das doenças.

Em artigo que discute a revalorização da epidemiologia descritiva por meio das doenças emergentes, BARATA ${ }^{4}$, 1997, traça o perfil da epidemiologia de acordo com o tempo. Nas décadas de 40 e 50, pela evolução de doenças parasitárias e infecciosas em doenças crônicas, a 
epidemiologia consolidou seu aspecto analítico, intensificando assim o desenvolvimento da metodologia aplicada. Nesta época, a metodologia de inquérito epidemiológico e estatística descritiva parecia não necessitar maiores refinamentos. Em conseqüência dos programas de vacinação em massa iniciados na década de 50, aconteceu o desinteresse da administração pública americana e perda de importância política dos órgãos de vigilância sanitária na década de 80 , levando ao desmantelamento dos órgãos de saúde pública por cortes na verba a eles destinada. Na década de 70, iniciou-se um rápido processo de urbanização na América, Ásia e África, que de forma desordenada agrupou em determinadas regiões um milhão de pessoas onde anteriormente não havia estrutura para tal. Este evento acarreta, geralmente, mudança no perfil de morbidade, levando ao aparecimento de novas doenças e agravos à saúde geral em decorrência de doenças anteriormente controladas. Assim, a epidemiologia descritiva assume importância na apresentação de informações sobre distribuição de casos, segundo tempo, espaço e pessoas, para que se proceda uma análise de dados a fim de propiciar o entendimento de uma determinada alteração e a resolução da mesma. Na epidemiologia um passo fundamental para reconhecer seu comportamento é descrever precisamente sua ocorrência na população, possibilitando dessa forma a elaboração de fatores causais baseados na ocorrência usual e a utilização de analogias para o entendimento de doenças. Abordagens descritivas são tidas muitas vezes com menos científicas ou menos sofisticadas, fato este que não reflete a importância e relevância das questões teóricas, conceituais ou metodológicas envolvidas neste tipo de estudo.

PINTO $^{54}$, 2000, iniciou suas observações sobre a epidemiologia expondo os conceitos de vários autores. Definiu epidemiologia como o estudo ordenado das causas e efeitos biológicos e sociais das doenças em populações humanas, tendo a comunidade, e não o indivíduo, como unidade 
de interesse. Citou SUSSER ${ }^{63}$, 1973, "Epidemiologia é o estudo da distribuição e dos determinantes da saúde em populações humanas". Afirmou que LAST $^{28}$, 1988, conceituou de forma mais abrangente como "o estudo da distribuição e determinantes de estados ou eventos relacionados à saúde em populações específicas, e sua aplicação no controle de problemas de saúde", justificando que a epidemiologia não se preocupa apenas com os aspectos e indicadores negativos, mas também com indicadores positivos de saúde e com maneiras de promovê-la. Citou PEREIRA ${ }^{51}$, 1995, que afirmou "Epidemiologia é o ramo das ciências da saúde que estuda, na população, a ocorrência, a distribuição e os fatores determinantes dos eventos relacionados com a saúde". Ressaltou sua importância embasando-se em fatos históricos, como na determinação do padrão de disseminação da cólera e sua associação com o abastecimento de água em Londres no ano de 1855, a associação entre o tabaco e asbesto no aumento no risco de desenvolvimento de câncer de pulmão, do bócio e cretinismo com uso de iodo, e o controle da cárie dentária com o uso do flúor. Ao discutir as diferenças entre os termos pesquisa e estudo, ressaltou a maior formalidade e academicismo do primeiro sem contudo diferi-los quanto à importância de ambos. Nos estudos observacionais, o pesquisador não interfere no curso natural do evento, sendo os estudos descritivos fornecedores de informações que poderão ser usadas em estudos analíticos, onde são testadas hipóteses, com o objetivo de se explicar causas e efeitos.

Ao abordar os estudos epidemiológicos, MENDONÇA ${ }^{38}, 2001$, reafirmou sua importância no controle de doenças, tendo estes estudos relevância quando aplicados do ponto de vista da saúde pública. Um grande desenvolvimento da metodologia epidemiológica aconteceu após a segunda guerra mundial, quando a epidemiologia buscou a identificação de fatores causais de doenças crônicas e fatores de risco da vida adulta. Observou-se um processo de aproximação da epidemiologia à clínica, com um enfoque 
centrado no indivíduo. Esta evolução tem sido debatida por vários autores, sendo apoiada pelos que afirmam seu papel nos avanços experimentados por estudos de determinadas enfermidades, e criticada por aqueles que afirmam não haver dignificação da epidemiologia ao estudar um micro-ambiente, pois a abordagem individual não elucida muitas questões que são de ordem social, cultural, econômica ou ambiental. Houve um contraste entre os achados em estudos epidemiológicos e a confirmação destes em laboratório, pois por algum tempo não havia conhecimento suficiente nem capacidade tecnológica para tal. Atualmente o que se experimenta é justamente o oposto pois a velocidade no desenvolvimento de determinados ramos da ciência acontece de forma espantosa. O cuidado na interpretação de resultados, quando se integram diferentes áreas à epidemiologia, torna-se parte fundamental na confirmação de hipóteses, tornando este processo mais complexo. A maioria dos autores estudados afirma que a epidemiologia caminha para um novo salto de conhecimento, devido à incorporação destas novas áreas de conhecimento na determinação da relevância de fatores no processo saúde/doença.

COLUSSI; FREITAS ${ }^{9}$, 2002, realizaram levantamento bibliográfico avaliando os estudos epidemiológicos sobre a condição de saúde bucal de pacientes idosos, buscando não somente a determinação da condição de saúde bucal destes pacientes, mas também procederam uma análise da metodologia empregada em tais estudos. Foram encontrados 29 artigos de 1988 a 2002, indexados nas bases de dados BBO, LILACS e MEDLINE, e deles obtidas informações quanto à metodologia (faixa etária, tipo de amostra, forma de apresentação dos dados) e resultados apresentados (índice CPO-D, percentual de dentes extraídos, percentual de edêntulos e uso e necessidade de prótese). Foi possível a observação na disparidade de dados apresentados, e principalmente na metodologia aplicada a cada estudo, não ficando claros alguns dados da metodologia como seleção e 
representatividade da amostra, critérios aplicados em diferentes classificações e terminologia. Primeiramente, foi possível a constatação da condição de saúde bucal precária destes pacientes, uma vez que os valores obtidos indicam um CPO-D de 26,8 a 31,0, com grande participação do componente "extraído(s)" (84\%) e alto índice de edêntulos (68\%). Outra conclusão a que os autores chegaram é que existe a necessidade de padronização na elaboração, execução, apresentação e análise dos resultados de inquéritos epidemiológicos, possibilitando assim uma comparação mais adequada de dados.

\subsection{Importância das alterações e condições sistêmicas e do exame clínico}

MARTINS et al. ${ }^{35}, 1997$, analisaram a prevalência da hipertensão, segundo gênero e faixa etária, em grupos classificados segundo critérios sócio-econômicos e caracterizou as prevalências segundo o tipo de ocupação. A amostra foi formada por 1.041 indivíduos de ambos os gêneros, maiores de 20 anos, e correspondeu à soma das amostras representativas de "áreas de estudo", estabelecidas por critérios sócio-econômicos e geográficos. Foram definidos estratos sociais, obedecendo a um gradiente de níveis sócio-econômicos, a partir do estrato I (alto) até o IV (baixo). Os padrões de referência utilizados para a definição da hipertensão foram os do Joint National Committee (JNC), 140/90 mmHg, e da Organização Mundial da Saúde (OMS), 160/95 mmHg. De acordo com os padrões do JNC as prevalências entre os homens foram as seguintes: estrato (I+II), 59,7\%, estrato III, 50,1\% e estrato IV, $65,5 \%$. Para os padrões da OMS, $47,2 \%, 38,8 \%$ e $55,7 \%$, respectivamente. Entre as mulheres, para os padrões do JNC, os percentuais foram: no estrato (I+II), $40 \%$, no estrato III, $56 \%$ e no estrato IV, $55 \%$, e pelos da OMS, $38 \%, 48 \%$ e $46 \%$, respectivamente. As prevalências 
entre os homens pertencentes à população economicamente ativa, quando classificados segundo tipo de ocupação, tiveram o seguinte comportamento: profissionais autônomos, formados por microempresários, pequenos comerciantes e profissionais liberais apresentaram uma prevalência entre $59,9 \%$ (JNC) e $37,2 \%(\mathrm{OMS}$ ); operários especializados e empregados em indústrias e oficinas, cerca de 48,2\% (JNC) e 36,6\% (OMS); os assalariados do setor de serviços, 34,6\% (JNC) e 13,7\% (OMS); os autônomos-diaristas, trabalhadores não especializados e desempregados, e 58,6\% (JNC) e 40,2\% (OMS). Para as mulheres pertences à população economicamente ativa, segundo padrões JNC e da OMS, respectivamente, obteve as seguintes prevalências: 35,0 e 27,2\%. Para as não pertencentes: 46,8 e 46,6\%.

Essas diferenças foram estatisticamente significantes em relação ao conjunto, para o padrão JNC, e para o padrão OMS. Os resultados contrariam a hipótese de que a mulher integrada ao mercado de trabalho torna-se mais exposta aos fatores de risco de doenças não transmissíveis. Concluiu-se que nessa população a hipertensão é um grave problema de saúde pública, com importante determinação social e que tem peculiaridades próprias no que se refere aos homens e às mulheres.

Após revisão da literatura sobre diabetes, JOWETT; CABOT ${ }^{26}, 1998$, destacaram a importância da atenção ao atendimento de pacientes diabéticos sob tratamento à base de insulina, pela ocorrência de crises hipoglicêmicas dos mesmos. Devido ao tratamento medicamentoso aplicado a estes pacientes, associado ao controle da dieta, estes pacientes estão sob maior controle dos níveis glicêmicos, mas expostos a quadros recorrentes de hipoglicemia. Quando tais níveis caem abaixo do limite de normalidade, o paciente diabético pode apresentar quadros hipoglicêmicos de diferentes severidades, expressando-se de quatro formas: assintomático, que ocorre de forma subclínica, em nível bioquímico apenas; moderado, podendo ser tratado pelo próprio paciente; severo, com necessidade de assistência médica; muito 
severo, resultando em convulsões ou coma. Reportam ainda que, num estudo envolvendo uma população de pacientes diabéticos, 10\% sofreram coma em período inferior a 24 meses anteriores, e que de 2 a $3 \%$ vieram a óbito em conseqüência da crise hipoglicêmica. Desta forma, o conhecimento acerca do diabetes e o reconhecimento de crises hipoglicêmicas é de suma importância não somente ao paciente e familiares, mas principalmente para os profissionais da área de saúde, incluído os cirurgiões-dentistas, atualmente mais propensos a se depararem com um paciente nestas condições.

Também em 1998, TRINDADE et al. ${ }^{67}$ avaliaram a prevalência de hipertensão arterial sistêmica na população urbana da cidade de Passo Fundo, RS, por meio de estudo observacional, descritivo e transversal de base populacional de uma amostra aleatória significativa da população em estudo. O critério para hipertensão arterial sistêmica foi $160 / 95 \mathrm{mmHg}$ e a média das últimas três aferições da pressão arterial foi utilizada para a análise de uma amostra composta por 206 indivíduos. Houve correção dos níveis pressóricos em relação ao diâmetro do braço e a entrevista foi feita com questionários padronizados. A prevalência da hipertensão arterial sistêmica foi de 21,9\% utilizando o critério de 160/95 mmHg somado aos pacientes normotensos em uso regular de medicação anti-hipertensiva. Dos 45 indivíduos hipertensos, $53,3 \%$ tomavam medicação anti-hipertensiva regularmente, sendo que $20 \%$ estavam com a pressão arterial controlada. Da população em estudo, 4,4\% eram diabéticos, 33,0\% fumantes, 31,4\% mulheres usando anticoncepcional oral, 2,9\% abusando de álcool, 29,6\% obesos. Foi encontrada associação significativa com a hipertensão arterial sistêmica, em relação à idade, obesidade e diabetes e não com referência ao gênero, cor, abuso de álcool, fumo e uso de anticoncepcional oral. Concluíram então que a prevalência da hipertensão arterial sistêmica em Passo Fundo está dentro dos limites esperados para tal; no entanto, o grau de controle desta população está em um nível muito aquém do satisfatório. 
Com o objetivo de descrever características de pacientes diabéticos acompanhados em um posto de atenção primária à saúde, ARAÚJO et al. ${ }^{1}$, 1999, realizaram estudo transversal, onde rastrearam 3.024 prontuários de família, em busca de pacientes com idade entre 30 e 75 anos, com diagnóstico de diabetes, atendidos nos últimos cinco anos. Os pacientes detectados foram entrevistados em seus domicílios, e compareceram ao posto para o exame físico e requisição para dosagem da hemoglobina glicosilada. A prevalência de diabetes foi de $4,2 \%$. A maioria eram mulheres brancas, ao redor dos 50 anos de idade, com renda familiar mensal inferior a três salários-mínimos. Menos de um terço seguia dieta, apenas um quinto fazia exercícios regulares, cerca de $70 \%$ estavam em uso de hipoglicemiantes orais ou insulina e dos que fizeram o exame (adesão de 70\%), a maioria apresentou níveis normais ou aceitáveis de glicemia. Dessa forma concluíram que maior esforço deve ser despendido pelas equipes de saúde de forma a promover a adesão dos pacientes diabéticos à dieta e ao exercício.

Por meio de revisão de literatura, EMERY; GUTTENBERG ${ }^{11}, 1999$, focaram seu estudo na importância do exame clínico na prevenção de emergências médicas no consultório odontológico, e também nas condições e alterações que potencializam a ocorrência destas emergências. Relatam que em uma amostra de 4309 de cirurgiões-dentistas houve o relato de 30.602 emergências num período de dez anos, e que 38\% destas aconteceram durante extrações dentárias. O número de pacientes que apresentam maior risco de situações de emergência tende a aumentar visto que a idade média dos pacientes em tratamento odontológico também tende a apresentar elevação, e conseqüentemente estes pacientes potencialmente apresentam mais alterações de saúde geral. Estudos demonstram que de 53 a $68 \%$ de todos os pacientes odontológicos apresentam ao menos uma alteração médica importante. Portanto uma anamnese elaborada com questões simples 
mas relevantes, associada a uma entrevista bem conduzida, nortearão o cirurgião-dentista quanto aos riscos que o paciente pode apresentar frente ao tratamento odontológico. Igualmente importante, o exame físico permitirá uma aferição direta de dados sobre o quadro de saúde geral do paciente, possibilitando assim a detecção de omissões, intencionais ou não, de dados pelo paciente. O exame físico apresenta não somente o caráter preventivo, mas é de grande importância na vigência de uma emergência médica, situação na qual a aferição de sinais vitais torna-se imprescindível para o restabelecimento ou manutenção da vida do paciente, até o momento em que o mesmo possa receber atendimento médico apropriado. Tão importante quanto os meios de obtenção de informações, pela anamnese e exame físico, é a habilidade e capacidade do cirurgião-dentista em interpretar essas informações, avaliando assim a relação risco-necessidade do procedimento a ser instituído, a necessidade de exames mais específicos para melhor avaliação da saúde geral do paciente, a capacidade do paciente suportar 0 estresse psicológico e físico do tratamento odontológico, a necessidade de haver preparação em relação a uma situação específica ou risco em potencial.

LEE; McWILLIANS; JANCHAR ${ }^{30}$, 1999, publicaram estudo sobre o atendimento odontológico de gestantes, suas principais alterações bucais durante o período gestacional e cuidados requeridos no atendimento destas pacientes. É fato que a gestação, embora não seja uma condição patológica, encerra uma série de alterações que exigem maiores cuidados tanto no atendimento e manutenção da saúde bucal da própria gestante, quanto na saúde do feto. Devido uma série de alterações hormonais, a gestante pode apresentar patologias características, como por exemplo a gengivite gestacional ou o granuloma piogênico. Contudo, deve ser esclarecido à paciente que a mística de se perder um dente por gestação não encontra embasamento científico. É imperativo que se propicie uma condição de saúde bucal satisfatória, bem como para quaisquer outros pacientes, não podendo 
ser menosprezadas as necessidades de atendimento quando houver indicação. Ressalta-se a importância da determinação dos riscos do procedimento a ser instituído e a real necessidade de execução do mesmo, sendo que é preferível evitar o tratamento destas pacientes quando no primeiro trimestre da gestação, devido à ação teratogênica de alguns medicamentos e ao risco de indução a aborto espontâneo de outros, e no terceiro trimestre, devido a maior chance de hipotensão supina quando realizados procedimentos de longa duração. A gestante pode apresentar-se com hipertensão arterial, fato este de grande relevância pois de 5 a 10\% das gestantes apresentam esta alteração e ainda desta ser a principal causa de óbitos maternos na gestação. A hipertensão pode ocorrer por expressão de duas entidades distintas durante a gestação: a hipertensão arterial crônica, presente desde antes da concepção; e a eclampsia, uma emergência médica importante que pode resultar ainda em acidente vascular cerebral hemorrágico, encefalopatia hipóxica e tromboembolia. Assim, o cirurgiãodentista de ter conhecimento acerca destas possíveis alterações e riscos envolvidos no atendimento de gestantes.

Sobre o exame clínico, SHAMPAINE ${ }^{62}$, 1999, afirmou que é a partir dele que o cirurgião-dentista pode colher informações para tomar as medidas preventivas às emergências médicas, instituindo quaisquer modificações no plano de tratamento, e avaliar o impacto das situações de estresse que, muitas vezes, desencadeiam as situações de emergência para o paciente. Embora tais situações emergenciais não sejam freqüentes na prática odontológica, um terço destas são potencialmente perigosas à vida, justificando assim uma postura preventiva para minimizar as chances de ocorrência. Além disso, dados epidemiológicos apontam para um aumento na freqüência de reações adversas devido ao aumento da idade média da população em geral e, por conseguinte, dos pacientes que se submetem ao tratamento odontológico. Tal aumento nas ocorrências também pode 
acontecer pelo aumento na complexidade e duração do atendimento. O maior risco que pacientes idosos apresentam deve-se ao fato de que com o passar dos anos acontece a degeneração de tecidos e sistemas orgânicos, como o decréscimo do fluxo sanguíneo para o cérebro e rins, decréscimo do fluxo cardíaco, comprometimento do sistema imune. O uso de medicamentos e histórico de intervenções cirúrgicas podem também oferecer maior risco quando o paciente necessitar de algum tipo de intervenção. Conclui-se que um exame minucioso e sem negligências quanto as informações relativas ao quadro de saúde geral, história médica e sinais vitais do paciente, fornecem informações ao cirurgião-dentista para a prevenção de emergências médicas durante atendimentos e o torna apto a identificar o risco que o tratamento odontológico pode oferecer ao paciente, sendo assim um passo muito importante para a prática segura da odontologia.

MARZOLA $^{36}, 2000$, relatou a importância de se proceder um exame clínico minucioso previamente à adoção de qualquer intervenção para o paciente. Um exame bem conduzido permite ao cirurgião-dentista a identificação de alterações de ordem local ou sistêmica que possam incorrer em maior risco à saúde do paciente, podendo por vezes oferecer risco à saúde geral ou à vida do paciente. Portanto, o exame físico e a anamnese tornam-se imprescindíveis, pois é neste momento em que se pode identificar sinais e/ou sintomas de diversas alterações ou condições, como diabetes, hipersensibilidade, hipertensão arterial, discrasias sangüíneas, gestação ou radioterapia, que podem se tornar contra-indicações ao ato cirúrgico. Ressalta ainda que estas contra-indicações, devido ao avanço dos métodos diagnósticos, medicamentos e modalidades terapêuticas, muitas vezes são relativas sendo assim passíveis de adequação do quadro de saúde do paciente para o recebimento do procedimento a ser realizado, ou ainda não influentes ao procedimento planejado desde que a alteração detectada seja avaliada e o atendimento autorizado pelo serviço médico competente. 
Para a determinação da prevalência do uso de drogas entre adolescentes de escolas de segundo grau, com base em um delineamento transversal, foi realizado estudo em 1998, em Pelotas, RS, por TAVARES; BÉRIA; LIMA ${ }^{64}$, 2001. Um questionário anônimo, auto-aplicado em sala de aula, foi respondido por uma amostra proporcional de estudantes com idade entre 10 e 19 anos, matriculados no primeiro grau (a partir da $5^{\text {a }}$ série) e no segundo grau, em todas as escolas públicas e particulares na zona urbana do município que tinham segundo grau. Foram entrevistados 2.410 estudantes e o índice de perdas foi de $8 \%$. As substâncias mais consumidas, alguma vez na vida, foram álcool $(86,8 \%)$, tabaco $(41,0 \%)$, maconha $(13,9 \%)$, solventes $(11,6 \%)$, ansiolíticos (8,0\%), anfetamínicos $(4,3 \%)$ e cocaína $(3,2 \%)$. Os meninos usaram mais do que as meninas maconha, solventes e cocaína, enquanto elas usaram mais ansiolíticos e anfetamínicos. Uso no mês, uso freqüente, uso pesado e intoxicações por álcool foram mais prevalentes entre os meninos. Após controle para fatores de confusão, permaneceu positiva a associação entre uso de drogas e turno escolar noturno, maior número de faltas à escola no mês anterior e maior número de reprovações escolares. Esta associação não foi positiva apenas para o álcool e o tabaco. Contudo o "uso pesado" do tabaco superou o do álcool, e demonstrou tendências de crescimento ou de estabilização. Destaca-se também uma tendência de equilíbrio do uso pesado de tabaco entre os gêneros, ao contrário do observado anteriormente onde o predomínio era do gênero masculino. Concluiu-se que a prevalência de experimentação de drogas em adolescentes escolares é alta, além de demonstrar que o uso do tabaco é inferior somente ao do álcool.

Segundo dados do Ministério da Saúde ${ }^{39}$, 2002, as doenças cardiovasculares são a principal causa de mortalidade no Brasil, com $27 \%$ dos registros de mortes, superando as doenças infecto-contagiosas. Não existe 
uma causa única para estas doenças, mas sim fatores de risco que aumentam a probabilidade de sua ocorrência. Dentre estes fatores destacam-se a hipertensão arterial e o diabetes.

A hipertensão arterial afeta de 11 a $20 \%$ da população adulta acima dos 20 anos de idade, e é definida como pressão arterial sistólica igual ou maior que $140 \mathrm{~mm} / \mathrm{Hg}$ e/ou pressão arterial diastólica igual ou maior que $90 \mathrm{~mm} / \mathrm{Hg}$ em indivíduos que não estão fazendo uso de medicação antihipertensiva, padrões estes definidos durante III Consenso Nacional de Hipertensão Arterial. Ressalta-se a importância da inclusão de outros fatores, como concomitância do diabetes, histórico familiar e doença renal, na determinação do risco de desenvolvimento de doenças cardiovasculares para os portadores de hipertensão arterial.

O diabetes pode ser definido como uma síndrome de etiologia múltipla, decorrente da falta de insulina e/ou incapacidade da insulina exercer adequadamente seus efeitos. Caracteriza-se por hiperglicemia crônica, alterando o metabolismo normal de carboidratos, lipídeos e proteínas. Acomete $12 \%$ da população entre 30 e 39 anos de idade, e cerca de $46,5 \%$ dos indivíduos desconhecem serem portadores da doença.

TOMITA et al.$^{65}$, 2002, ao avaliar as condições periodontais e sua relação com o diabetes na população nipo-brasileira, examinaram 1.315 indivíduos do município de Bauru, SP, na faixa etária de 30 a 92 anos de idade, de ambos os gêneros, da primeira (Isseis) e segunda (Nisseis) gerações. Os critérios de exclusão da amostra foram o edentulismo total e a presença de seis sextantes nulos. $O$ índice periodontal comunitário e o índice de perda de inserção periodontal foram obtidos mediante sondagem em dez dentes-índice, em uma amostra de 831 indivíduos. O diagnóstico de diabetes foi estabelecido por meio da glicemia em jejum e de duas horas após sobrecarga com $75 \mathrm{~g}$ de glicose. Quanto às condições periodontais, foram encontrados $25,5 \%$ de indivíduos sadios, $12,5 \%$ com sangramento à 
sondagem, 49,4\% com presença de cálculo, 10,4\% com bolsas superficiais, $2,2 \%$ com bolsas profundas. Apresentaram perdas de inserção periodontal de 0-3mm, 24,2\% dos indivíduos, de 4-5mm, 36,7\%, de 6-8mm, 23,7\%, de 9 $11 \mathrm{~mm}, 11,3 \%$ e de $12 \mathrm{~mm}$ ou mais, $4,1 \%$. A avaliação entre diabetes e condições periodontais não apresentou associação estatística, embora os indivíduos com diabetes tenham maiores percentuais de bolsas profundas e perdas de inserção maiores que $6 \mathrm{~mm}$ que os não diabéticos. Concluíram assim que abordagem epidemiológica da condição periodontal e sua associação com doenças sistêmicas, como o diabetes, pode oferecer importante contribuição para prevenir suas complicações.

MALCON; MENEZES; CHATKIN ${ }^{32}$, 2003, em estudo sobre tabagismo, buscando determinar sua prevalência e fatores de risco em uma população de jovens, determinaram por meio de estudo transversal aplicado a uma amostra de 1187 adolescentes de 10 a 19 anos residentes na cidade de Pelotas, RS, que a prevalência do uso de tabaco para a população estudada foi de $12,1 \%$. Contudo a prevalência para "fumo alguma vez na vida" foi superior, alcançando uma porcentagem de $26 \%$. Em relação à faixa etária do início do uso do tabaco, 55\% o fizeram entre 13 e 15 anos de idade, e 22,5\% entre 7 e 12 anos. Observaram também que a maioria fumava há mais de um ano, somente 9,3\% fumavam há menos de um ano, e 56\% consumiam em média mais de cinco cigarros por dia. Foi possível também a determinação de um perfil para o adolescentes com maior risco de se tornar um usuário de tabaco: baixa escolaridade, reprovou três ou mais vezes na escola, possuía três amigos fumantes ou mais e possuía pai, mãe e/ou irmãos mais velhos fumantes.

\subsection{Dados relativos às exodontias}


Ainda que a odontologia atual busque a prevenção de lesões e a conservação e manutenção de cada dente, e ainda que tenham sido desenvolvidos novas técnicas e materiais com esta finalidade, a exodontia continua sendo um procedimento amplamente praticado e necessário em nosso país. FERREIRA JÚNIOR ${ }^{12}$, 1997, em estudo que resgatou, além de outras informações, o número de pacientes atendidos e os procedimentos aplicados a estes pacientes no Serviço de Urgência Odontológica da Faculdade de Odontologia de Bauru, Universidade de São Paulo, constatou que foi realizado o atendimento de 30.918 pacientes no período de 1987 a 1995. Estes atendimentos culminaram em 21.252 tratamentos, dos quais $5.406(17,48 \%)$ foram exodontias. Observou-se que este procedimento foi 0 segundo mais praticado, sendo superado apenas pelos $6.870(22,22 \%)$ casos de abertura coronária.

MARZOLA ${ }^{36}, 2000$, afirmou que a falta de um ou mais dentes diminui o poder de mastigação, altera a estética facial e pode alterar a fisiologia da articulação temporomandibular, causando distúrbios funcionais e psíquicos ao indivíduo. Dessa forma, uma exodontia não deve ser indicada sem que antes tenham sido esgotadas todas as possibilidades de manutenção do dente, objetivando sempre a saúde do paciente.

\subsubsection{Causas determinantes de exodontias}

Segundo GREGORI ${ }^{21}$, 1996, algumas situações tornam a extração de um dente necessária, sendo elas: (1) dentes que, em virtude de processos patológicos e/ou traumatismos, não podem ser mantidos por um tratamento conservador; (2) dentes que interferem com a reabilitação protética de pacientes já mutilados pela perda de outros dentes; (3) dentes mal posicionados no arco dentário (dentes ectópicos) que não possam ser recuperados por correção ortodôntica; (4) dentes supranumerários e dentes 
decíduos não-esfoliados que de alguma forma não são inócuos ao paciente; (5) dentes associados a patologias que venham receber tratamento médico de ordem radical ou conservadora. $O$ autor ressalta ainda que existem situações clínicas que ocorrem independentemente da acentuada evolução que a Odontologia vem apresentando em terapêutica conservadora.

De acordo com HADDAD et al. ${ }^{24}$, 1999, as principais causas determinantes para exodontia variam de acordo com a região estudada. Embora a cárie seja a principal em algumas áreas, em outras a doença periodontal é a causa mais prevalente. Contudo, estas são as duas principais causas apontadas pela maioria dos estudos.

MARZOLA $^{36}, 2000$, ao descrever as causas determinantes de exodontias, de modo mais abrangente, cita como causas as seguintes situações:

Dentes com foco de infecção sem possibilidade de tratamento endodôntico, sendo a apicoplastia contra-indicada

Indicação bastante reservada, tendo em vista os avanços nas técnicas endodônticas e cirurgias periodontais, e a necessidade da associação de condições que impeçam a realização de ambos;

Dentes decíduos que retardam o irrompimento do permanente

Esta situação pode levar ao irrompimento do dente permanente fora da sua posição normal, sendo então uma indicação profilática das más oclusões; Periodontopatias avançadas

Quando for observada reabsorção óssea alveolar muito acentuada (mais de um terço em relação à raiz do dente), sendo necessárias observação e avaliação criteriosas, clínica e radiograficamente;

Razões protéticas 
Quando após a perda de vários dentes, as condições bucais não satisfaçam os requisitos necessários para a instalação de peça protética, principalmente quando das próteses parciais removíveis;

Dentes não restauráveis

Quando o dente apresentar lesão de tal extensão que torne impraticável qualquer forma de restauração;

\section{Dentes retidos}

Quando for observado dente que não irá irromper, quando não houver espaço, bem como quando estiverem provocando acidentes nervosos, mecânicos, mucosos ou neoplásicos;

Dentes retidos e impactados

Pela situação incorreta no arco dentário, o dente irá exercer ação mecânica sobre os dentes vizinhos, podendo levar a reabsorção de suas raízes;

\section{Dentes supranumerários}

Por influírem na articulação normal, causando má-oclusão ou mesmo retenção de determinados dentes;

\section{Razões ortodônticas}

É indicada a extração de um ou mais dentes quando a ortodontia necessita criar espaço para corrigir uma má-oclusão ou evitar seu aparecimento;

\section{Dentes com raízes fraturadas}

Quando houver fratura da raiz do dente em porções média ou apical, a linha de fratura pode levar a instalação de processo infeccioso, sendo indicada a exodontia após constatação de impossibilidade do tratamento endodôntico; Raízes residuais

Dentes incluídos em neoplasias benignas

Devem ser extraídos dentes contidos no interior da neoplasia, ou mesmo aqueles adjacentes que estejam em área que deva ser removida para o tratamento adequado da lesão; 
Dentes relacionados com infecções do seio maxilar

Indicada a exodontia para a remoção do foco de infecção primário, quando se tornar inviável outra terapêutica para tal dente;

Dentes que traumatizam tecidos moles

Indicada quando não houver possibilidade de impedimento do trauma causado por este dente aos tecidos moles adjacentes;

Dentes localizados em regiões que sofrerão radioterapia

Nestes casos é necessária uma avaliação bastante criteriosa quanto às condições que o dente apresentará a longo prazo, devido às alterações que estarão presentes após iniciada a radioterapia (diminuição da irrigação sanguínea - aumentando o risco de osteorradionecrose - e da salivação aumentando o risco de cárie).

\subsubsection{Dados epidemiológicos relativos às exodontias}

ECKERBON; MAGNUSSON; MARTINSSON ${ }^{10}$, 1992, constataram que estudos longitudinais sobre a perda dentária são raros, mas as razões para a perda dentária têm sido estudadas por muitos autores. Realizaram estudo que descreveu as causas e a incidência de perdas dentárias de uma população previamente descrita de 200 pacientes, em duas ocasiões, com um intervalo de 5 a 7 anos, e observou-se que as causas de extrações estavam relacionadas a próteses ou problemas endodônticos. Foi observado que 197 dentes (4\%) dos 4889 registrados no primeiro exame foram extraídos durante este intervalo. Dos dentes extraídos, 65 (33\%) eram endodonticamente tratados, e destes, 44 (68\%) apresentavam um ou mais condutos preenchidos até $2 \mathrm{~mm}$ ou mais do ápice e 29 (43\%) foram considerados insatisfatoriamente obturados. Em 93 dos 197 dentes extraídos foi possível determinar a causa da exodontia a partir da ficha do paciente. Concluiu-se que a perda dentária foi igualmente distribuída nas faixas etárias e que molares e pré-molares foram mais extraídos que dentes anteriores. Dentes tratados endodonticamente são 
mais comumente perdidos que os demais e o tratamento insatisfatório aumenta o risco de necessidade de exodontia, enquanto dentes portadores de coroas não apresentam aumento deste risco. Finalmente, a cárie foi a principal causa de exodontia.

REICH; HILLER ${ }^{55}$, 1993, colheram informações sobre as principais causas de perda dentária nos estados do oeste da Alemanha de acordo com cirurgiões-dentistas generalistas de clínicas particulares. Dos 80 cirurgiõesdentistas selecionados aleatoriamente da região de interesse, 68 enviaram informações relativas a extrações de dentes permanentes realizadas em duas semanas de atendimento, num total máximo de 20 pacientes por cirurgiãodentista. Foram avaliados 882 questionários, de 926 retornados, com informações das extrações de 1215 dentes. A distribuição das freqüências de causas determinantes para exodontias foi: cáries 20,7\%; doença periodontal 27,3\%; combinação de cárie e doença periodontal 18,7\%; terceiros molares $14,7 \%$; razões protéticas $11,2 \%$; razões ortodônticas $4,1 \%$; traumatismos $0,4 \%$; e outras causas 2,9\%. Enquanto a cárie foi a causa mais freqüente em todos os outros grupos, a doença periodontal e a combinação de ambas foram mais freqüentes nos grupos acima dos 40 e 45 anos, respectivamente. $O$ dente mais freqüentemente extraído foi o terceiro molar. Os pacientes foram questionados quanto ao motivo da extração e a principal razão foi a dor $(47,2 \%)$.

Em estudo de MORITA ${ }^{42}$, 1994, envolvendo cirurgiões-dentistas japoneses que anotaram as causas de cada extração de dente permanente realizada durante uma semana em cada uma das quatro estações do ano, foram relatadas as causas determinantes de um total de 11175 dentes extraídos. As causas foram divididas em seis grupos: cárie, doença periodontal, problemas de erupção, trauma, razões ortodônticas e outras causas. A cárie foi a causa mais comum $(55,4 \%)$, seguida pela doença 
periodontal (38\%). As mulheres perderam mais dentes por cárie que os homens. Nas faixas etárias acima dos 15 anos, a cárie também foi a principal causa de exodontia. As razões periodontais foram a principal causa somente para o gênero masculino entre 46 e 65 anos de idade. Os dentes anteriores, principalmente inferiores, foram os mais submetidos a exodontia em conseqüência de doença periodontal. Os dentes superiores posteriores foram extraídos por cárie tanto quanto por doença periodontal para o gênero masculino, enquanto para o gênero feminino a cárie foi a causa mais freqüente.

GUIMARÃES; MARCOS ${ }^{22}$, 1995, realizaram estudo que envolveu indivíduos de 11 a 70 anos de idade, onde 357 pacientes foram examinados e classificados como pertencentes à classe social alta ou à baixa. Após exame clínico, foram determinadas as causas que indicavam a necessidade de exodontia. A cárie foi a principal causa com 42\%, seguida pela doença periodontal e indicação protética com $26 \%$ e $25 \%$, respectivamente, e com as demais causas (indicação ortodôntica, erupção, traumatismo, e outras causas) totalizando $7 \%$. No entanto, quando foram levadas em conta as diferenças entre os dois grupos de classes sociais, pode-se observar a seguinte situação para a distribuição das causas na classe alta: cárie, 10,8\%; doença periodontal, 36,7\%; indicação protética, 1,3\%; outras causas, 51,3\%. Para a classe baixa a distribuição das causas expressou-se da seguinte maneira: cárie, 45,2\%; doença periodontal, 24,6\%; indicação protética, 28,3\%; outras causas, 1,9\%. Reforçando a diferença no padrão de perda dentária nas classes sociais, a cárie e a doença periodontal foram responsáveis por menos da metade do total de indicações na classe alta, com 47,5\% das indicações, enquanto na classe baixa foi responsável por $69,8 \%$. Ao analisar as diferenças entre as faixas etárias nos dois grupos, de 11-40 anos de idade houve diferença no padrão de perda dentária uma vez que na classe alta 93\% das indicações foram por "outras causas" e a cárie por somente 7\%. Já na classe 
baixa, a principal causa foi a cárie, responsável por $52,4 \%$ das indicações. Acima dos 40 anos de idade a principal indicação para ambas as classes foi a doença periodontal. Concluíram então que a distribuição da perda dentária relacionada com as causa biológicas está fortemente influenciada pela condição sócio-econômica.

Posteriormente, GUIMARÃES; MARCOS ${ }^{23}$, 1996, determinaram os dentes potencialmente perdidos (DPP) destes pacientes, pela soma dos dentes extraídos e dentes com indicação para extração. Observou-se que na classe alta os DPP até os 40 anos é de 4 e o número dobra acima desta idade. Na classe baixa há uma mudança no padrão uma vez que há o aumento contínuo do DPP até 40 anos, estabilizando-se a partir desta idade. A comparação entre as duas classes demonstra que o DPP para a classe baixa $(15,29)$ é 2,5 vezes maior que para a classe alta $(6,14)$. A análise de regressão linear revelou que aos dois anos de vida já existe um dente potencialmente perdido na classe baixa, e aos 20 anos 1/3 da dentição está potencialmente perdida, ficando as pessoas potencialmente desdentadas aos 60 anos. Para a classe alta, apenas aos 15 anos há a projeção de 1 DPP, 1/3 da dentição perdida aos 43 anos e aos 60 anos, 14 DPP. Deste modo, concluíram que a projeção da perda dentária na classe baixa é extremamente mais grave que na classe alta.

Em levantamento realizado por ONG; YEO; $\mathrm{BHOLE}^{48}, 1996$, determinaram-se as causas de exodontia de dentes permanentes em uma população de Cingapura. Os dados foram obtidos de 52 cirurgiões-dentistas generalistas durante um período de 12 meses. Foram obtidos dados de 1276 pacientes, dos quais foram extraídos 272 dentes. Deste grupo de pacientes as porcentagens de dentes extraídos em conseqüência de cárie e de doença periodontal foram semelhantes, sendo $35,8 \%$ e $35,4 \%$ respectivamente. Houve um aumento de dentes extraídos por doença periodontal com o aumento da 
idade. Em pacientes acima dos 40 anos de idade um total de $76 \%$ dos dentes perdidos foram por razões periodontais. No entanto, observou-se o contrário em relação à cárie. Dentes posteriores foram mais freqüentemente extraídos em relação aos anteriores. Terceiros molares somaram $24,7 \%$ dos dentes extraídos enquanto os incisivos centrais apenas $8 \%$ de todas as exodontias. Molares foram os dentes mais extraídos em conseqüência de cáries e os dentes inferiores anteriores os mais extraídos por razões periodontais. Este estudo não demonstrou uma causa predominante para exodontia, pois cárie e doença periodontal foram causas equivalentes na determinação de exodontias.

O estudo realizado por MURRAY; CLARKE; LOCKER ${ }^{43}$, 1997, envolvendo 165 cirurgiões-dentistas generalistas, forneceu informações sobre 6134 pacientes atendidos durante uma semana, em clínicas particulares em Ontário, Canadá. Destes pacientes $11,6 \%$ tiveram um ou mais dentes permanentes extraídos. Razões periodontais foram a causa de 35,9\% destas extrações e a cárie de $28,9 \%$. Em relação ao tipo de dente, o terceiro molar foi o dente mais extraído. Porém, houve diferença do tipo de dente extraído entre a faixas etárias. Os dentes posteriores foram mais freqüentemente extraídos nos jovens, enquanto os anteriores o foram nos mais idosos. Houve também diferenças quanto à causa da extração segundo o tipo de dente. A comparação dos resultados deste estudo com os de um estudo similar realizado na Escócia sugerem que a idade e o tipo de dente não foram relevantes para o excesso de extrações por doença periodontal nesta população canadense. Diferenças entre padrões e atitudes dos cirurgiões-dentistas talvez tenham sido fatores contribuintes.

Segundo $\mathrm{ONG}^{47}$, 1998, dados epidemiológicos recentes demonstram uma tendência do aumento de perdas dentárias em conseqüência de problemas periodontais comparada à cárie. Foram feitas as seguintes 
observações em relação à doença periodontal e perda dentária no estudo realizado pelo autor. A presença de perda de aderência inicial, reabsorções alveolares e o tabagismo aumentam significativamente o risco de perda dentária. Existe uma forte correlação entre tabagismo, severidade da doença periodontal e perda dentária. Estudos populacionais transversais apontam os dentes anteriores inferiores como os mais freqüentemente extraídos por razões periodontais, seguidos pelos anteriores superiores e segundos molares superiores. No entanto, em estudos longitudinais, os molares são extraídos com mais freqüência. As causas periodontais que mais comumente levam à exodontia são mobilidade acentuada e lesão de furca. A cirurgia periodontal não aumentou a preservação de dentes em grupos de alto risco. Em conclusão, a perda dentária por causas periodontais está associada com a perda do ligamento periodontal, e grupos de risco com periodontite avançada contribuem para uma grande perda dentária em uma minoria da população.

Com o objetivo de determinar o perfil sócio-econômico de pacientes adultos submetidos à exodontia na clínica de graduação da Faculdade de Odontologia de Piracicaba, UNICAMP, bem como as causas determinantes de exodontia, suas prevalências e presença de histórico alteração sistêmica dos pacientes, MOREIRA et al. ${ }^{41}, 1998$, realizaram estudo envolvendo 80 pacientes. Destes pacientes 31\% eram do gênero masculino e $69 \%$ do feminino, e a distribuição segundo faixas etárias foi de $21,13 \%$ para paciente abaixo dos 20 anos, $19,72 \%$ de 20 a 30 anos, $26,76 \%$ entre 30 e 40 anos, $14,08 \%$ de 40 a 50 anos, $11,27 \%$ de 50 a $60,5,63 \%$ de 60 a 70 anos e $1,14 \%$ acima de 70 anos, com idade média de 34 anos. Foram realizadas as extrações de 115 dentes e, após determinadas as causas destas exodontias, onde não foram consideradas no estudo as extrações de dentes decíduos, terceiros molares ou qualquer dente não irrompido, a cárie foi a causa de $68 \%$ das exodontias, doença periodontal de $14 \%$, razões protéticas $6 \%$, razões 
ortodônticas 4\% e outras causas $8 \%$. Constataram que $83 \%$ dos pacientes atendidos não apresentavam doença sistêmica, e 17\% eram portadores de ao menos uma alteração de saúde. Dos pacientes portadores de alteração sistêmica cinco apresentavam hipertensão arterial, dois apresentavam cardiopatia, dois diabetes, dois bronquite, um anemia, um hipotensão arterial e um apresentava reumatismo.

GABRE; MARTINSSON; GAHNBERG ${ }^{15}$, 1999, tiveram como objetivo investigar as causas e a incidência da perda dentária num período de dez anos em uma população de deficientes mentais adultos que recebiam atendimento odontológico regularmente. O número de dentes de 115 indivíduos, com idade média, em 1984, de 41 anos e variação de 19 a 83 anos, foi registrado em 1984 e 1994. As causas de perdas dentárias, utilização de medicamentos, freqüência de consultas odontológicas e cooperação durante o tratamento dentário foram anotadas e relacionadas com a perda dentária. A média de perda dentária durante o período foi de 3,72, e a média de consultas para exame odontológico foi de 6,6 por ano. A maioria dos 428 dentes extraídos teve indicação de exodontia em conseqüência de doença periodontal (58\%). Observaram também que os cuidados odontológicos oferecidos não foram suficientes para controlar doenças bucais. Os dados indicaram que a conquista da cooperação durante o atendimento odontológico não apenas torna este atendimento possível, mas também permite a diminuição de perdas dentárias.

O estudo de GILBERT et al. ${ }^{17}$, 1999, teve por objetivos descrever a incidência de perda dentária em uma amostra de adultos durante um período de 24 meses, e correlacionar fatores clínicos, comportamentais e sóciodemográficos à perda dentária. Foi realizado um estudo longitudinal, onde foram examinados pacientes que possuíam ao menos um dente na boca, 45 anos de idade ou mais e residiam no norte da Flórida. Foi realizada uma 
entrevista e um exame clínico ao início do estudo e 24 meses após, com consultas por telefone a cada seis meses do início do estudo. Uma regressão linear geral hierárquica de dois níveis foi usada para quantificar os fatores dentários específicos e nível pessoal simultaneamente. Das 739 pessoas que foram atendidas e examinadas nos 24 meses, $24 \%$ perderam um ou mais dentes. A perda dentária foi mais comum em pessoas com doenças dentárias no exame inicial, sinais e sintomas dentários incidentais, com atitudes negativas com relação aos cuidados e saúde dentários, com recursos financeiros limitados, idosos, negros, do gênero feminino, e que procuravam tratamento odontológico quando havia problema. Contudo a presença de doenças dentárias ao exame inicial foi o fator mais associado à perda dentária. Não houve fator predominante na determinação de extrações dentárias. Aparentemente a perda dentária é o resultado de uma complexa interação entre doença dentária, sinais e sintomas dentários incidentais, tendência de procura atendimento odontológico em resposta de algum problema específico presente, atitudes em relação aos dentes e capacidade de dispor de alternativas de atendimento não extracionista.

WORTHINGTON; CLARKSON; DAVIES ${ }^{70}$, 1999, realizaram estudo prospectivo com a finalidade de descrever a incidência de extrações dentárias em um grupo de adultos atendidos regularmente e avaliar os fatores predictivos na perda dentária. Foram obtidos dados clínicos iniciais e anuais de 23 cirurgiões-dentistas, sobre um grupo de seus pacientes adultos regularmente atendidos, durante um período de cinco anos. Os pacientes responderam um questionário onde havia dados sobre a saúde bucal relativos a comportamento, atitude e conhecimento, e fatores sociais. Foram obtidos dados sobre 2799 pacientes. Destes, 470 (17\%) submeteram-se a exodontias, das quais $72 \%$ foram de dentes posteriores. A maioria das extrações teve como causa a cárie (79\%). Houve diferença estatisticamente significante entre aqueles pacientes que se submeteram a exodontias e os que 
não se submeteram, a respeito de variáveis clínicas, sociais e comportamentais. O modelo de regressão logística incluía três variáveis clínicas: número de dentes, próteses e sítios de recessão. Outras variáveis no modelo final incluíam o prognóstico do cirurgião-dentista e do paciente quanto à necessidade de tratamento, presença de sensibilidade dentária, hábito de ingestão de açúcar, morar só e tabagismo. Este estudo demonstrou não só a importância de fatores clínicos, mas como de outros fatores no prognóstico de quem irá submeter-se a exodontias.

$\mathrm{NICHOLLS}^{45}, 2000$, determinou a incidência de doença periodontal na clínica odontológica generalista particular e avaliou a efetividade do tratamento na prevenção da perda dentária, durante um período de 12 anos. Durante um período de seis meses, de fevereiro a agosto de 1997, foram colhidos dados de pacientes que foram examinados de setembro de 1985 a setembro de 1986, em uma clínica generalista particular de Bournemouth. Os dados referiam-se ao número de dentes presentes no início do período pesquisado, aqueles que possuíam profundidade de sondagem entre 5 e $6 \mathrm{~mm}$, e aqueles que possuíam profundidades superiores a $7 \mathrm{~mm}$. Quando algum destes dentes era extraído, a data da extração foi anotada. Durante o período do estudo os pacientes receberam tratamento odontológico convencional. No início do tratamento, 13\% dos 157 pacientes envolvidos no estudo apresentavam problemas periodontais. Foram anotados 3.778 dentes no início do tratamento, e após tratamento convencional foram extraídos apenas 151 dentes (4\%).Concluiu-se que a doença periodontal afeta um pequeno número de pacientes da clínica odontológica generalista, e os pacientes afetados respondem bem à terapia convencional resultando em poucas perdas dentárias durante o período estudado.

Em estudo realizado por BRENNAN; SPENCER; SZUSTER ${ }^{7}, 2001$, o objetivo foi avaliar a associação de exodontias com os diagnósticos de cárie, 
infecção pulpar ou periapical e doença periodontal, de acordo com o tipo de atendimento e idade. Os dados foram colhidos por meio de questionários aplicados aos pacientes atendidos em um dia comum de funcionamento do consultório particular de cirurgiões-dentistas generalistas da Austrália, aleatoriamente convidados a participar da pesquisa. Foram colhidos dados de 8154 pacientes dos quais $7,05 \%$ foram submetidos a exodontias. As principais causas de exodontia foram a doença periodontal (17,45\%) e a cárie $(7,90 \%)$. A probabilidade de extração foi maior em atendimentos de urgência que em tratamentos de rotina. Em relação à idade, as maiores probabilidades de exodontia, correlacionando a causa à idade, foi a cárie para indivíduos de 18 a 44 anos de idade, infecção pulpar ou periapical para todas as idades e a doença periodontal para indivíduos acima dos 45 anos de idade. Houve diferença estatisticamente significante para as causas específicas de exodontia por idade. Embora as conseqüências tenham sido maiores para a infecção pulpar ou periapical, a maior causa de exodontia continua sendo a cárie pela sua maior prevalência.

\subsubsection{Dados relativos aos terceiros molares}

Em estudo publicado por BISHARA ${ }^{6}, 1999$, foi discutida a influência dos terceiros molares inferiores no apinhamento dentário dos dentes anteriores inferiores, fatores influentes na impacção dos terceiros molares e condutas quanto à indicação de exodontia destes dentes, por meio de revisão de literatura.

Em relação ao apinhamento dos dentes incisivos inferiores, o autor apresentou uma série de artigos que não apresentaram indícios da associação entre a presença de terceiros molares inferiores em oposição a dois artigos que assim afirmavam. Citou também artigos onde o objetivo era avaliar a influência da exodontia de terceiros molares no apinhamento dos incisivos inferiores, e sugeriu que não há evidências de que este procedimento 
seja eficiente para tal objetivo. Desta maneira, o autor concluiu que os terceiros molares não desempenham papel importante no apinhamento anterior inferior.

Sobre a impacção dos terceiros molares, apresentou estudos que apontam para vários fatores morfológicos, como direção vertical de crescimento condilar, comprimento mandibular, erupção retrodirecionada da dentição inferior, maturação tardia dos terceiros molares, que podem determinar a impacção destes dentes. Destacou também que os meios empregados na tentativa de predicção de irrompimento ou impacção de terceiros molares não são suficientemente confiáveis, seja por meio de medidas de pontos de referência ou por meio da inclinação dos terceiros molares. O conjunto dos argumentos encontrados, em associação com o determinado nas conferências do Instituto Nacional de Pesquisas Odontológicas e da Associação Americana de Cirurgia Bucomaxilofacial, levaram ao consenso dos seguintes pontos: não há justificativa na indicação de exodontia com a finalidade de evitar ou minimizar o apinhamento anterior inferior; quando a terapia ortodôntica exigir movimentação posterior de segundos ou primeiros molares é justificada a indicação de exodontia dos terceiros molares; não há evidências de que os terceiros molares sejam necessários para o correto desenvolvimento das bases ósseas da mandíbula e da maxila; a exodontia, quando indicada, deve ser realizada preferencialmente em pacientes jovens, sem contudo justificar a remoção de germes dentários em crianças pela imprecisão dos meios de estimativa de erupção empregados; os pacientes devem ser informados dos risco inerentes ao procedimento cirúrgico quando este se fizer necessário.

Para os terceiros molares assintomáticos impactados e/ou mal posicionados, é consenso de que os mesmo apresentam-se em condições anormais e por isso sua extração é justificada. Em estudo realizado com a finalidade de determinar as causas de indicação de terceiros molares, foram colhidos dados de 870 pacientes tratados em 23 clínicas da Suécia. As 
razões apontadas para exodontia de terceiros molares inferiores foram: profilática (27\%), pericoronarite precoce (25\%), cáries e pulpites (25\%), ortodônticas (14\%), cistos, tumores e reabsorções radiculares (3\%) e outras razões (18\%). Os dados obtidos indicam que 54\% dos dentes eram assintomáticos.

GODFREY ${ }^{18}$, 1999, realizou estudo por meio de revisão bibliográfica sobre a remoção profilática de terceiros molares assintomáticos. Após análise de informações sob embasamento de argumentos clínicos de diferentes áreas da odontologia (cirurgia e traumatologia, periodontia e ortodontia) o autor concluiu que, embora tal discussão não aparente estar próxima de um consenso, os terceiros molares são susceptíveis ao desenvolvimento de patologia quando deixados in situ, e que quando a avaliação clínica culminar em prognóstico incerto acerca da remoção ou permanência é preferível optar pela primeira, preferivelmente durante a adolescência. Ressaltou ainda que o paciente deve ser esclarecido quanto à posição de seus terceiros molares, bem como sobre o prognóstico de erupção e posicionamento futuro dos mesmo.

Ainda em 1999, YAMAOKA et al. ${ }^{71}$ publicaram estudo com o objetivo de investigar a associação entre presença de terceiros molares impactados ou em erupção, idade e ocorrência de reabsorção em segundos molares. Foram examinadas 3883 radiografias de 3174 pacientes, onde os resultados permitiram aos autores concluir que não houve diferenças entre gênero e idade na incidência de reabsorção dos segundos molares. A presença de reabsorção do segundo molar foi mais freqüente na ocorrência de terceiro molar completamente impactado do que quando o terceiro molar apresentavase parcialmente irrompido. Reabsorção apical associada ao terceiro molar impactado foi mais observada em indivíduos com 50 anos de idade ou mais, e 
houve maior incidência de sobreposição e reabsorção radicular em homens que em mulheres.

SANT'ANA; FERREIRA JÚNIOR; PINZAN ${ }^{61}, 2000$, realizaram estudo com o objetivo de determinar a prevalência da posição dos terceiros molares inferiores não irrompidos nos pacientes atendidos na clínica de Cirurgia da Faculdade de Odontologia de Bauru, Universidade de São Paulo, no período de 1992 a 1997. Foram analisadas as posições de 800 dentes, as quais foram classificadas segundo critérios de WINTER, e a ordem das posições segundo as freqüências observadas foram vertical (45,75\%), mesioangular $(36,25 \%)$, distoangular $(8,125 \%)$, horizontal $(6,875 \%)$, invertido $(2,25 \%)$ e transalveolar $(0,75 \%)$. Concluíram também que a frequência de terceiros molares mesioangulados é maior em pacientes mais jovens e diminui à medida que a idade destes pacientes aumenta, mas que as freqüências das demais posições dos terceiros molares inferiores não se alteram.

Após revisão de literatura com o objetivo de avaliar a necessidade de exodontia de terceiros molares inferiores não irrompidos, BENOTTI ${ }^{5}, 2002$, apresentou dados a respeito da associação entre presença destes dentes e apinhamento inferior anterior, meios de predicção de erupção dos terceiros molares não irrompidos, probabilidade de desenvolvimento de patologia associada à presença de dentes não irrompidos, condição de saúde do paciente e risco da intervenção cirúrgica.

Embora houvesse autores que afirmavam o contrário, é aceito atualmente que a presença de terceiros molares inferiores não irrompidos não é determinante para o apinhamento dentário, sendo vista como condição concomitante. Dessa forma, há poucas evidências de que a exodontia dos terceiros molares beneficiará o paciente quando a intenção é evitar este transtorno ortodôntico. É consenso também que os meios atualmente empregados na previsão de irrompimento dos terceiros molares não 
irrompidos não são confiáveis, e por isso de relevância duvidosa na determinação das exodontias.

Mesmo que se saiba toda a gama de patologias que podem se desenvolver a partir de um dente não irrompido, muitos são os autores partidários de que este não é um argumento aceitável para a indicação de exodontia, uma vez que a freqüência de desenvolvimento destas patologias não foi esclarecida e que o procedimento de exodontia destes dentes, fundamentalmente cirúrgico, incorre em outros riscos para a saúde do paciente. Em contrapartida, é também grande o número de autores que atentam para o fato de que é necessário o esclarecimento do paciente quanto aos riscos de desenvolvimento de tais patologias, bem como os riscos inerentes ao procedimento cirúrgico, pois o consentimento e opção pelo tratamento cirúrgico é um direito assegurado do paciente.

Concluiu que a exodontia dos terceiros molares deve ser realizada diante da necessidade cirúrgica, sendo que esta é determinada pela presença de patologias associadas ou nas situações onde a posição anatômica gera uma maior susceptibilidade de desenvolvimento de condições patológicas futuras, e não pela simples presença de dentes não irrompidos ainda assintomáticos. A exodontia não deve ser opção terapêutica quando o paciente não apresentar condições que o permitam superar 0 trauma cirúrgico. Contudo, o grande número de estudos que apresenta posturas e opiniões contrárias sobre a necessidade de exodontia dos terceiros molares não irrompidos implica em análise, pelo profissional, dos riscos e benefícios de cada caso em particular.

Em 2002, VASCONCELLOS et al. ${ }^{68}$ analisaram 450 radiografias panorâmicas, onde foram observados um total de 1358 terceiros molares. A análise das radiografias foi realizada em uma clínica de radiologia odontológica, da cidade do Recife, PE, no período de agosto a outubro de 2001 e foram incluídos no estudo pacientes de ambos os gêneros, com idade 
entre 21 e 25 anos. Os terceiros molares não irrompidos foram classificados de acordo com a classificação de WINTER. Das radiografias observadas, 151 eram de pacientes do gênero masculino e 299 do feminino. Das 450, 287 radiografias apresentavam dentes não irrompidos, das quais 148 (32,88\%) eram do gênero masculino e 139 (30,88\%) eram do gênero feminino. Foi possível a observação de 1358 terceiros molares, onde 789 (43,83\%) estavam irrompidos e 569 (31,61\%) estavam não irrompidos/semi-irrompidos. A posição vertical foi a que apresentou maior frequêencia $(45,17 \%)$, seguida da mesial $(34,97 \%)$, distal $(11,78 \%)$, horizontal $(7,03 \%)$ e anômala $(1,05 \%)$. 
3 PROPOSIÇÃO 


\section{Proposição}

Este estudo teve por objetivo determinar, por meio de levantamento epidemiológico, o perfil dos pacientes atendidos nas clínicas da disciplina de Cirurgia da Faculdade de Odontologia de Bauru - USP, no período de 1997 a 2002, avaliando:

1. as características destes pacientes segundo gênero, idade, procedência, tipo de procedimento a que foram submetidos, acidentes e complicações, dados da história médica, pressão arterial aferida no atendimento e número de dentes extraídos;

2. as principais indicações para exodontias, suas prevalências e a distribuição destas segundo faixa etária dos pacientes. 
4 MATERIAL E MÉTODOS 


\section{Material e métodos}

Previamente ao início deste estudo, foram satisfeitas todas as exigências, normas e orientações estabelecidas pelo Comitê de Ética em Pesquisa da Faculdade de Odontologia de Bauru - USP.

O estudo foi realizado pela análise dos prontuários dos pacientes recebidos pelas clínicas de Cirurgia da Faculdade de Odontologia de Bauru - USP, no período de janeiro de 1997 a dezembro de 2002, totalizando 3927 prontuários.

A análise dos prontuários foi realizada por apenas um examinador, sendo este o próprio autor da pesquisa, por observação dos dados presentes nas fichas clínicas, radiografias e/ou fichas de solicitação de tratamento. O modelo da ficha clínica utilizada pela disciplina de Cirurgia da FOB-USP pode ser observado no Anexo 1.

Foram anotados, quando possível, os seguintes dados:

- gênero;

- idade;

- procedência;

- procedência da radiografia utilizada para o planejamento cirúrgico;

- data da radiografia;

- data da execução do procedimento;

- tipo de procedimento realizado;

- acidentes e complicações;

- dados da história médica;

- pressão arterial;

- número de dentes extraídos; 
- indicação da exodontia;

- classificação dos terceiros molares segundo os critérios de PELL e GREGORY ${ }^{50}$ e de WINTER ${ }^{69}$ (Figuras 1 e 2 ).
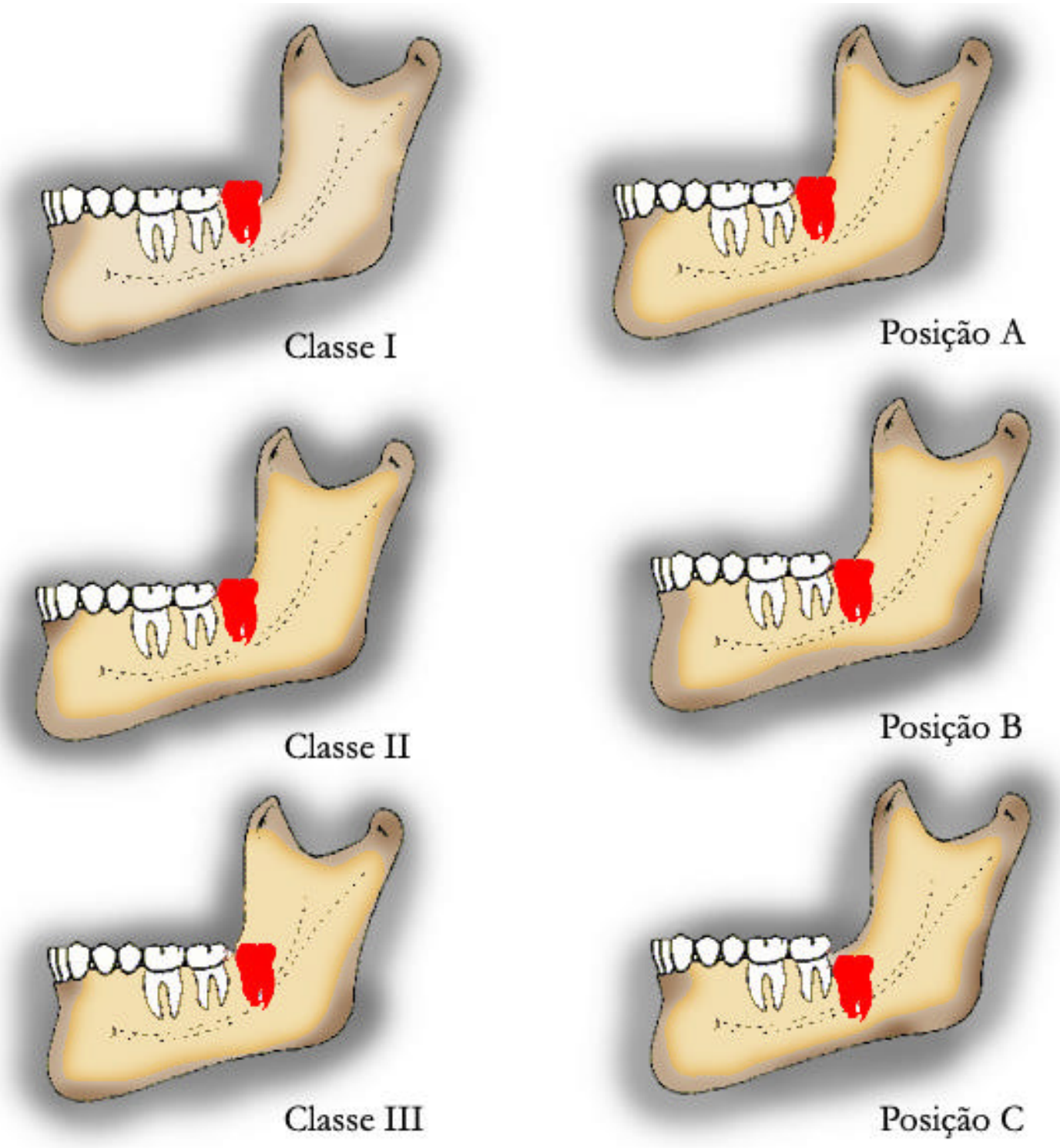

Figura 1 - Classificação da posição dos terceiros molares segundo PELL; GREGOR $\left.\right|^{50}$. 


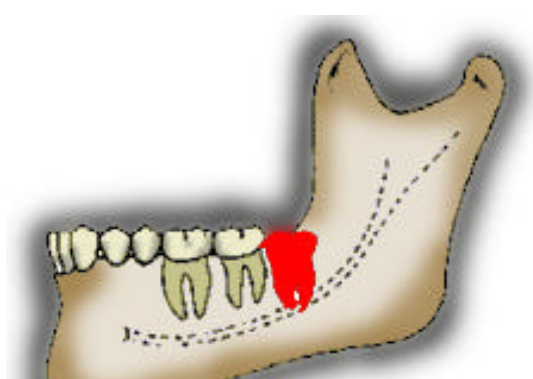

1 - Vertical
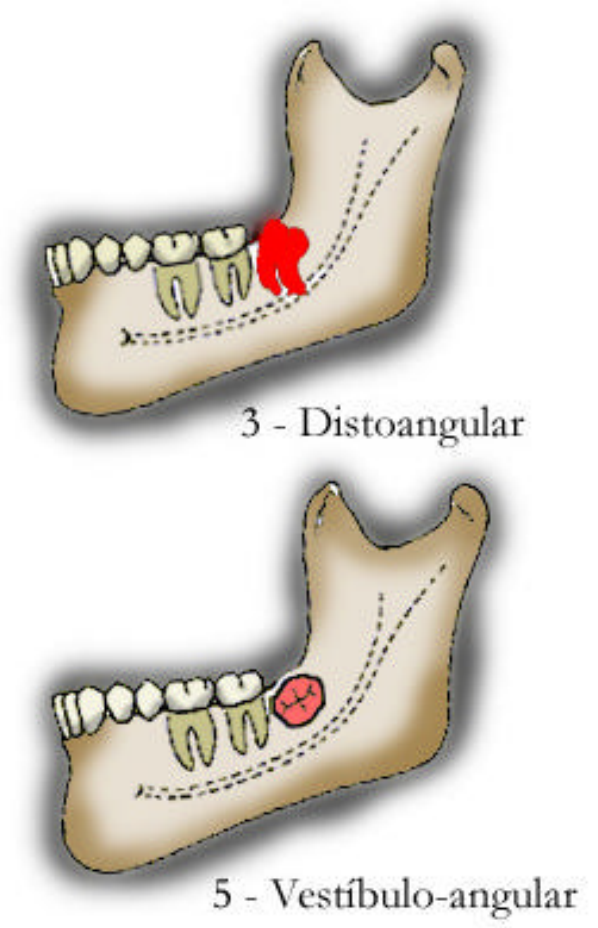
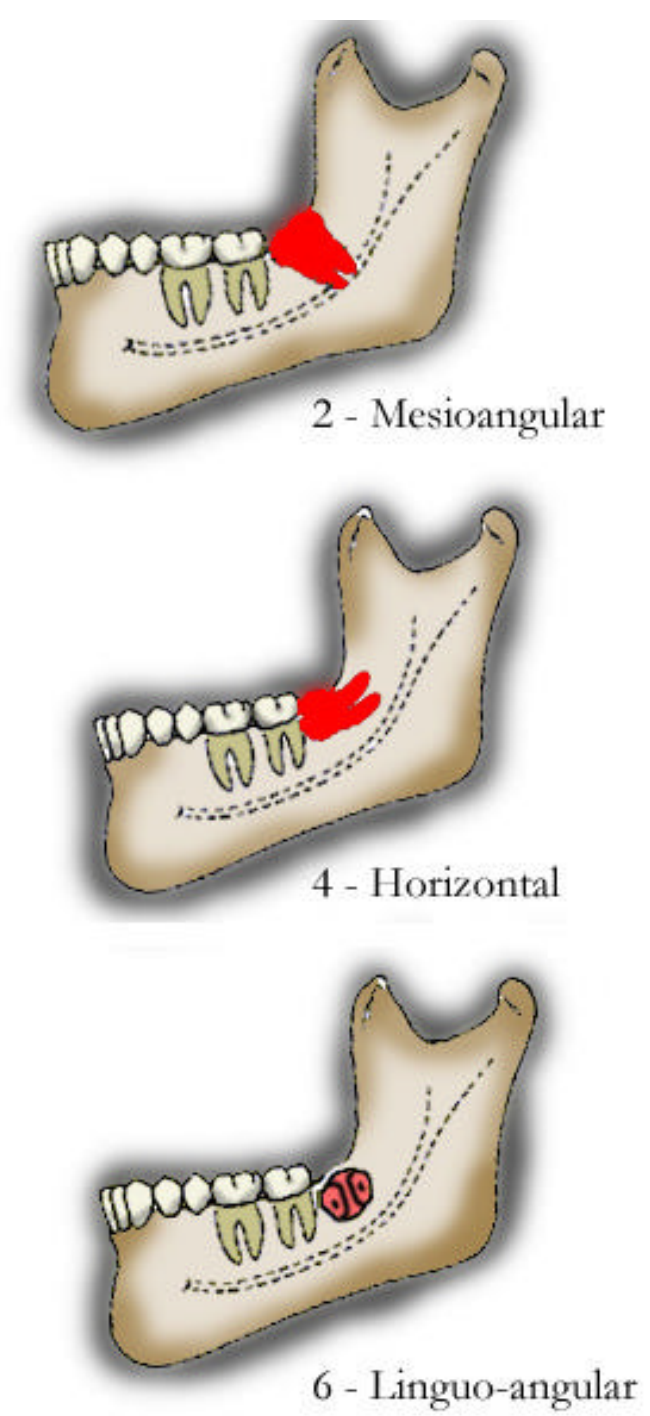

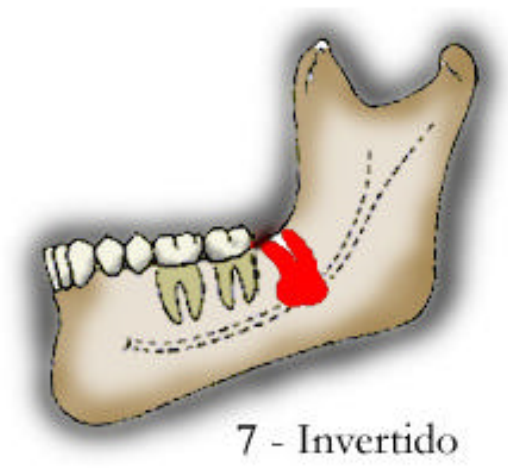

Figura 2 - Classificação da posição dos terceiros molares segundo WINTER ${ }^{69}$. 
Por utilizar radiografias panorâmicas na observação e classificação da posição dos terceiros molares, considerou-se como transalveolar as posições vestíbulo-angular e linguo-angular.

Para os dados da aferição de pressão sangüínea presentes nos prontuários foi aplicado o critério pelo Joint National Committee (JNC) e adotado pelo Ministério da Saúde (MS), pelo qual é considerada hipertensão arterial pressão sangüínea sistólica igual ou superior a $140 \mathrm{~mm} / \mathrm{Hg}$ e/ou pressão sangüínea diastólica igual ou superior a $90 \mathrm{~mm} / \mathrm{Hg}$.

A observação de radiografias foi realizada com utilização de negatoscópio em sala escura, e lente de aumento com magnificação de três vezes. Os dados obtidos foram anotados em tabela desenvolvida especificamente para este estudo em programa Microsoft Access (Microsoft Corporation).

As indicações das exodontias, quando não explicitadas no prontuário, foram identificadas pela observação de radiografias e fichas de solicitação de tratamento e classificadas em uma das seguintes categorias:

I. Cárie:

Quando havia lesão cariosa extensa e impossibilidade de reconstrução do dente;

II. Doença periodontal:

Quando havia reabsorção óssea alveolar atingindo o terço cervical da raiz, ou de maior extensão; 


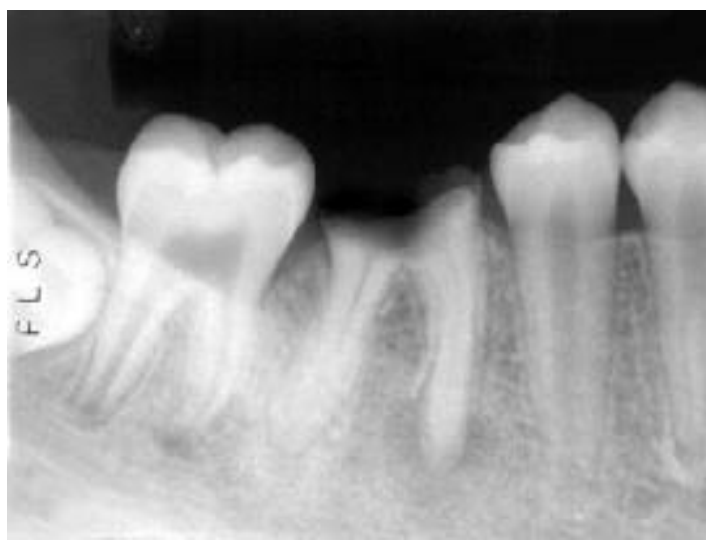

Figura 3 - Exemplo de dente com indicação para exodon-tia por cárie.

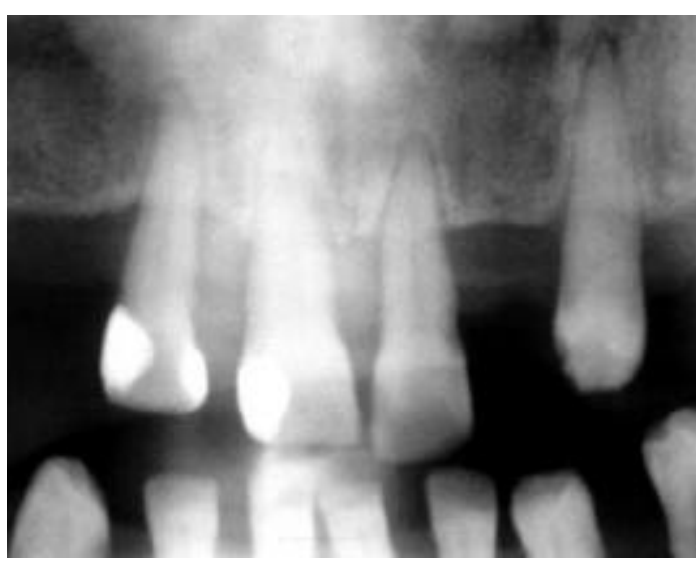

Figura 4 - Exemplo de dente com indicação para exodontia por doença periodontal.

III. Traumatismo dentário:

Quando havia fratura coronária, coronorradicular ou radicular, que inviabilizasse a permanência do dente;

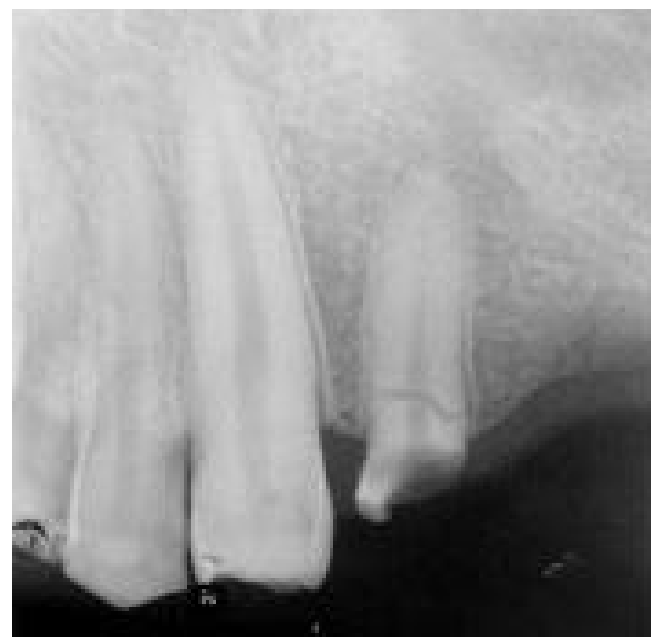

Figura 5 - Exemplo de dente com indicação para exodontia por traumatismo dentário. 
IV. Indicação protética:

Quando havia, no prontuário do paciente, solicitação de exodontia do dente em decorrência de planejamento protético;

V. Indicação ortodôntica:

Quando havia, no prontuário do paciente, solicitação de exodontia do dente em decorrência de planejamento ortodôntico;

VI. Dente não irrompido:

Quando havia um ou mais dentes não irrompidos sem espaço suficiente para seu correto posicionamento no arco dentário, ou quando seu posicionamento impedia o irrompimento;

VII. Dente supranumerário:

Quando havia um ou mais dentes supranumerários, irrompidos ou não, que causassem desaliamento de outros dentes do arco, alteração da articulação normal dos dentes ou impedisse o irrompimento de dentes permanentes;

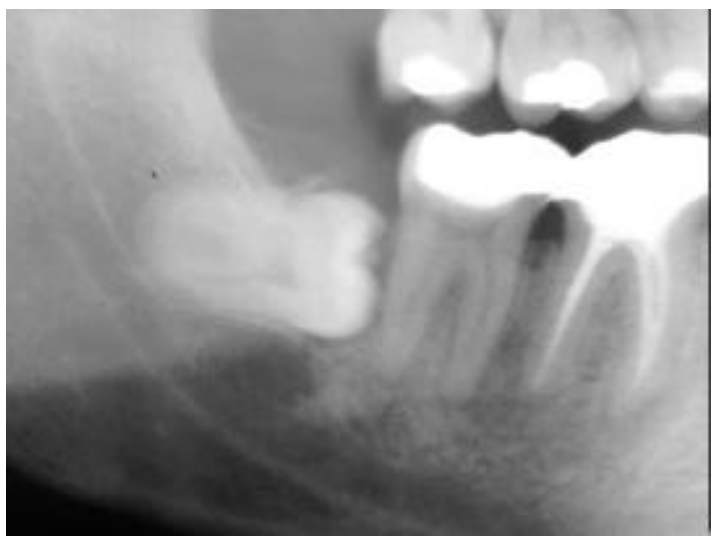

Figura 6 - Exemplo de dente não irrompido com indicação para exodontia.

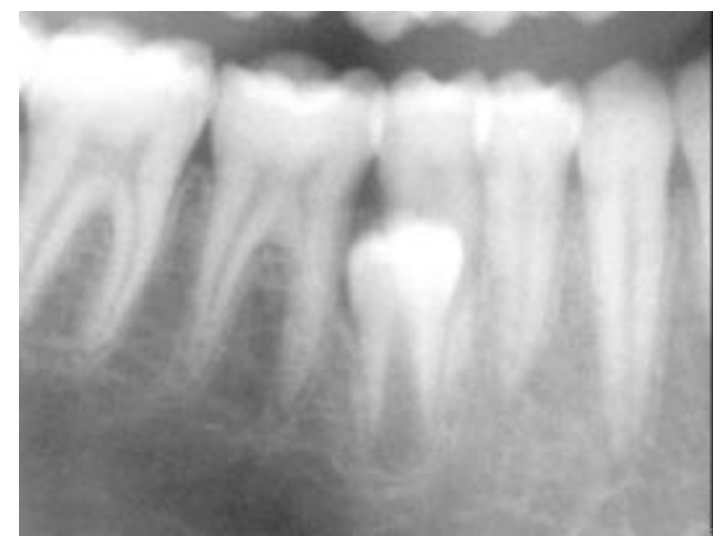

Figura 7 - Exemplo de dente supranumerário com indicação para exo-dontia. 
VIII. Dente decíduo persistente:

Quando havia a presença de dente decíduo em idade superior àquela em que deveria ter se esfoliado;

IX. Perfuração endodôntica:

Quando havia imagem compatível com trepanação durante o preparo endodôntico do canal;

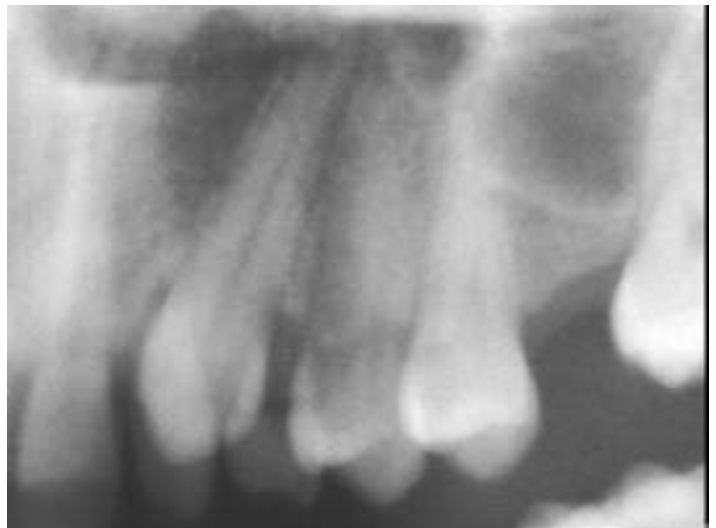

Figura 8 - Exemplo de dente decíduo persistente com indicação para exodontia.

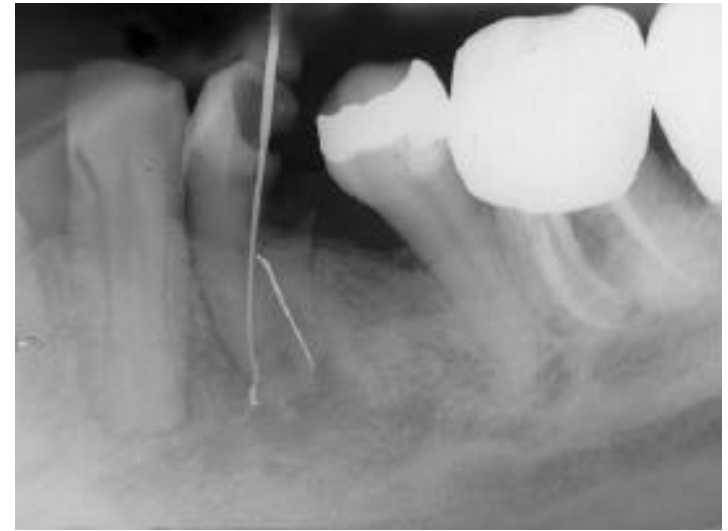

Figura 9 - Exemplo de dente com indicação para exodontia por perfuração endodôntica.

\section{Pericoronarite:}

Quando havia, no prontuário, evidência de processo inflamatório associado a um dente semi-irrompido, ou histórico desta ocorrência.

\section{Outras causas:}

Quando a indicação não pôde ser classificada em nenhuma das categorias.

Não foram considerados neste estudo os dentes ausentes, mesmo aqueles com histórico de exodontia prévia. Foram anotadas as indicações para exodontia dos dentes extraídos nas clínicas da disciplina de Cirurgia da FOB - USP e dos demais dentes observados nos prontuários. 
Os dados obtidos foram tabulados com 0 uso dos programas Microsoft Access e Microsoft Excel (Microsoft Corporation) (Figura 10).

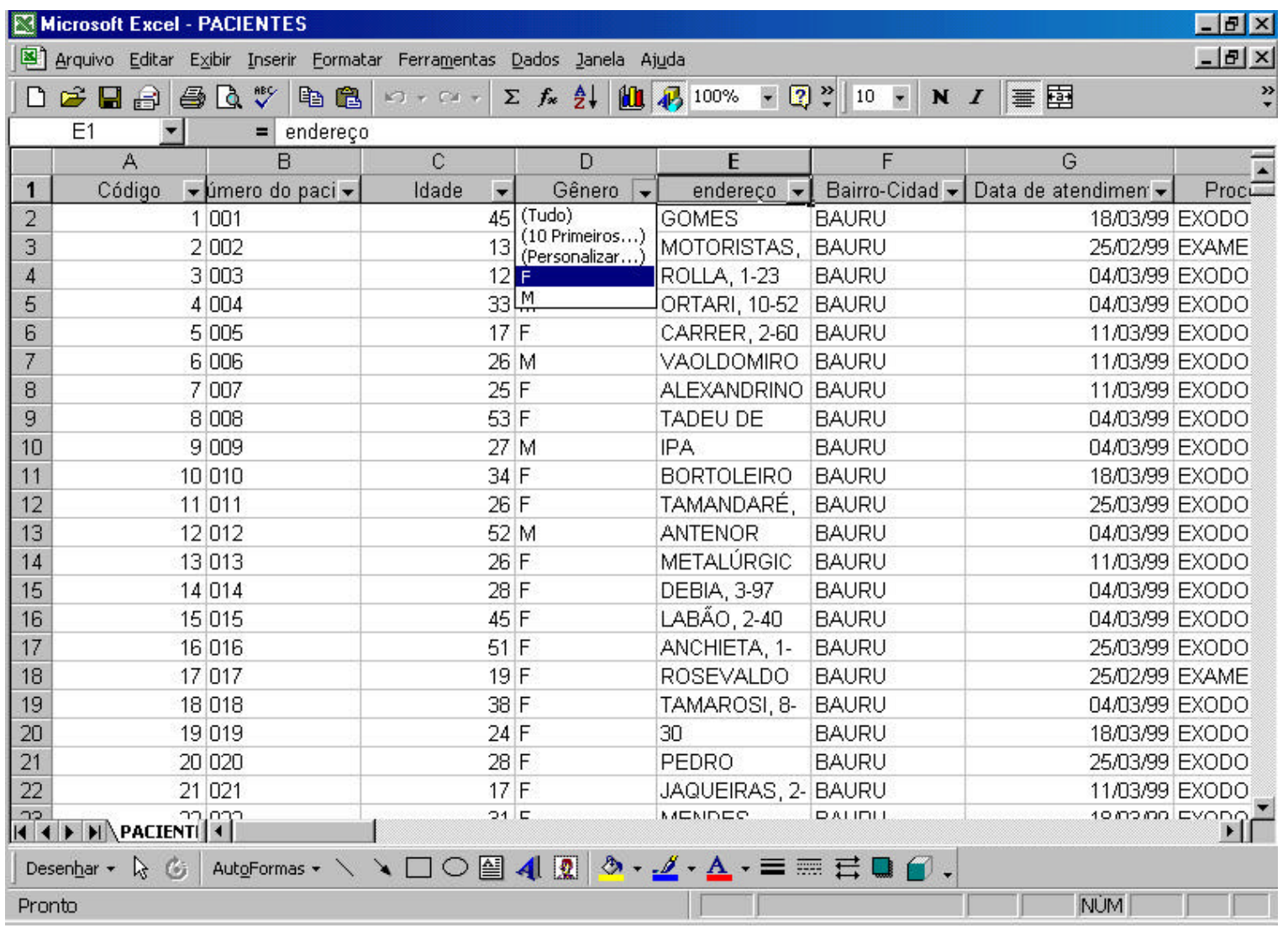

Figura 10 - Tela do programa Microsoft Excel no momento da aplicação de filtro para análise dos dados. 
5 RESULTADOS 


\section{Resultados}

Foram analisados os prontuários de 3927 pacientes recebidos no período de janeiro de 1997 a dezembro de 2002, dos quais 3588 foram incluídos na população de estudo e 339 foram desconsiderados por não fornecerem informações suficientes para sua inclusão ou não estavam presentes no arquivo da Disciplina de Cirurgia da Faculdade de Odontologia de Bauru-USP.

Dos 3588 prontuários que constituíram a população de estudo, 1396 (38,9\%) eram de pacientes do gênero masculino e $2192(61,1 \%)$ eram de pacientes do gênero feminino (Figura 11).

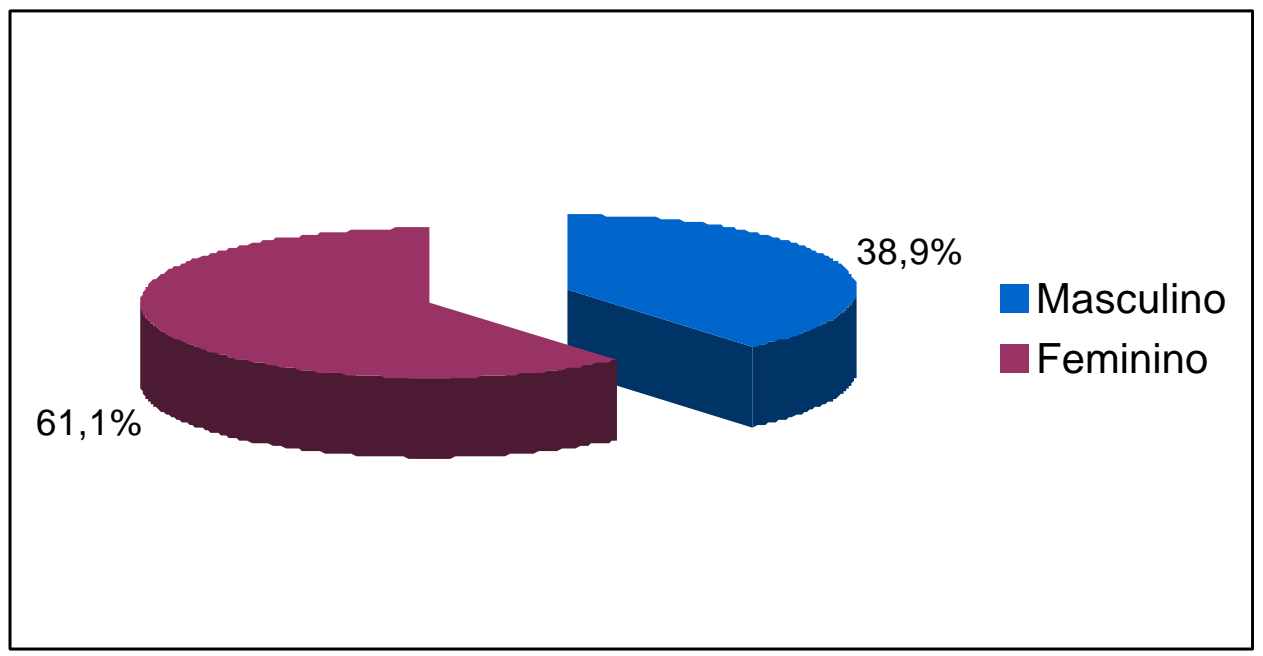

Figura 11 - Distribuição percentual dos pacientes atendidos nas clínicas da Disciplina de Cirurgia, segundo o gênero, no período de 1997 a 2002.

Foi possível determinar a idade de 2875 pacientes. A idade média foi de 31,3 anos, com variação de 7 a 102 anos. Foram anotadas as idades de 1775 pacientes do gênero feminino, com média de 30,6 anos, e de 1100 
do gênero masculino, com média de 32,4 anos. A distribuição dos pacientes conforme a faixa etária pode ser observada na figura 12.

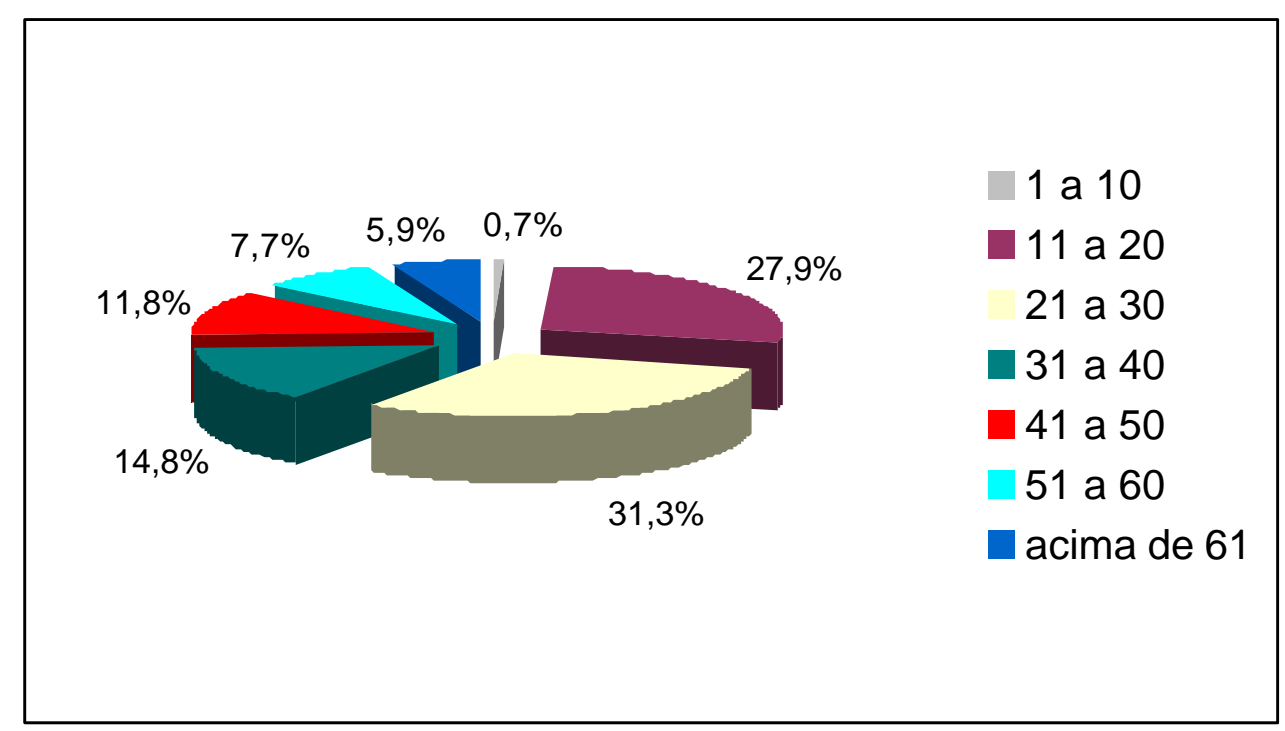

Figura 12 - Distribuição dos pacientes atendidos de acordo com faixa etária.

Em 2884 prontuários foi possível identificar a procedência dos pacientes. No anexo 2, pode-se observar o número de pacientes de todos os municípios atendidos. Os municípios com maior número de pacientes atendidos estão apresentados na tabela 1. 
Tabela 1 - Municípios com maior número de pacientes atendidos

\begin{tabular}{lc}
\hline \multicolumn{1}{c}{ Municípios de origem } & Número de pacientes \\
\hline Bauru & 2301 \\
\hline Agudos & 53 \\
\hline Lençóis Paulista & 53 \\
\hline Botucatu & 40 \\
\hline Piratininga & 33 \\
\hline Novo Horizonte & 25 \\
\hline Arealva & 23 \\
\hline Santa Cruz do Rio Pardo & 23 \\
\hline Duartina & 21 \\
\hline Pederneiras & 21 \\
\hline Pirajuí & 17 \\
\hline Espírito Santo do Turvo & 15 \\
\hline Presidente Alves & 13 \\
\hline São Manuel & 12 \\
\hline Jaú & 11 \\
\hline
\end{tabular}

Para os pacientes do município de Bauru, verificourse também de qual região do município eram provenientes. Estes dados podem ser observados na tabela 2 . 
Tabela 2 - Número de indivíduos atendidos por região de Bauru-SP

\begin{tabular}{lcc}
\hline \multicolumn{1}{c}{ Região } & Número de pacientes & Porcentagem \\
\hline Centro & 140 & $6,1 \%$ \\
\hline Norte & 643 & $27,9 \%$ \\
\hline Oeste & 681 & $29,6 \%$ \\
\hline Sul & 338 & $14,7 \%$ \\
\hline Leste & 446 & $19,4 \%$ \\
\hline Não informado & 53 & $2,3 \%$ \\
\hline Total & 2301 & $100 \%$ \\
\hline
\end{tabular}

2418 pacientes $(67,39 \%)$, realizaram as radiografias necessárias ao planejamento cirúrgico do caso na própria FOB-USP (figura 13). Observou-se ainda um período médio de 55,37 dias entre a tomada radiográfica e o dia do primeiro atendimento.

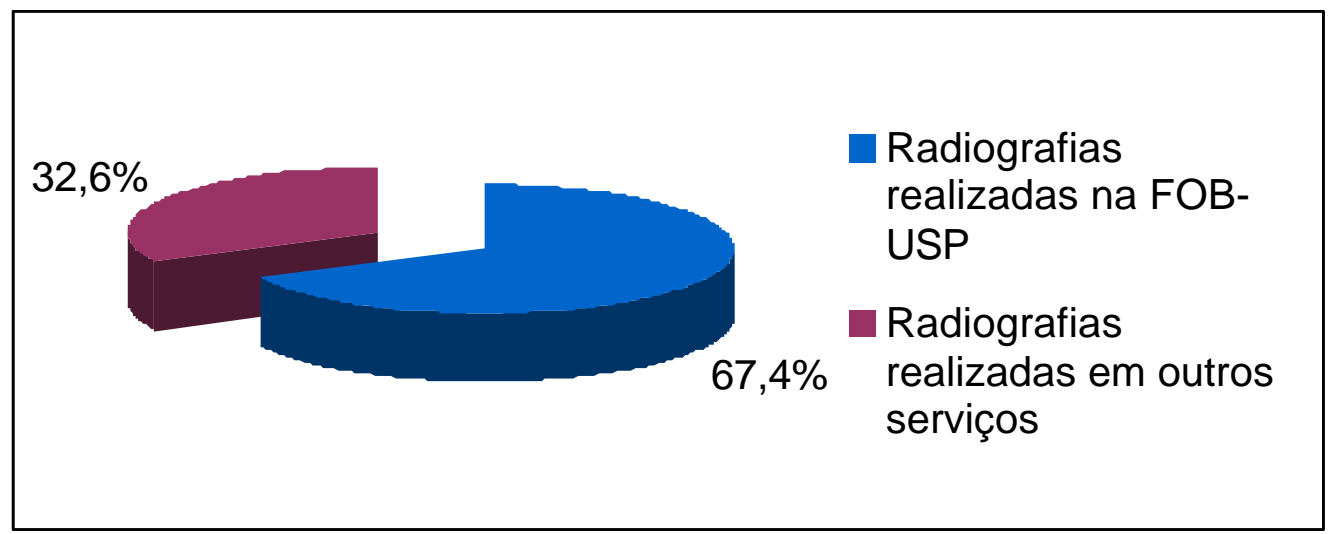

Figura 13 - Distribuição percentual da procedência das radiografias.

Dos 3588 prontuários analisados, em 702 (19,56\%) não havia informação sobre os procedimentos realizados, restando 2886 nos quais estavam registrados 2930 procedimentos que podem ser observados na tabela 3. 
Tabela 3 - Freqüência dos procedimentos realizados nas clínicas da disciplina de Cirurgia da FOB-USP, por tipo

\begin{tabular}{lccc}
\hline \multicolumn{1}{c}{ Procedimentos } & Masculino & Feminino & Total \\
\hline Exodontia & 921 & 1438 & 2359 \\
\hline Exame & 119 & 189 & 308 \\
\hline Biópsia & 33 & 91 & 124 \\
\hline Instalação de implantes & 12 & 12 & 24 \\
\hline Cirurgia avançada para implante & 11 & 13 & 24 \\
\hline Colagem cirúrgica de acessório & 11 & 14 & 25 \\
\hline para tracionamento & 9 & 10 & 19 \\
\hline Frenectomia & 4 & 10 & 14 \\
\hline Disjunção cirúrgica da maxila & 3 & 1 & 4 \\
\hline Remoção de implantes & 1 & 0 & 1 \\
\hline Cirurgia parendodôntica & 9 & 16 & 25 \\
\hline Cirurgia pré-protética & 1 & 2 & 3 \\
\hline Outros procedimentos & 1134 & 1796 & 2930 \\
\hline Total & & & \\
\hline
\end{tabular}

Nos prontuários de 92 pacientes submetidos a algum tipo de procedimento cirúrgico, foi possível identificar 94 acidentes ou complicações ocorridos durante ou após o procedimento realizado. A distribuição dos acidentes ou complicações está apresentada na tabela 4. 
Tabela 4 - Prevalência de acidentes e complicações

\begin{tabular}{|c|c|c|}
\hline $\begin{array}{l}\text { Tipo de acidente ou } \\
\text { complicação }\end{array}$ & $\begin{array}{l}\text { Número de } \\
\text { ocorrências }\end{array}$ & Porcentagem \\
\hline Alveolite & 28 & $0,97 \%$ \\
\hline Hemorragia & 22 & $0,76 \%$ \\
\hline Comunicação bucossinusal & 16 & $0,55 \%$ \\
\hline Parestesia & 7 & $0,24 \%$ \\
\hline Fratura de túber & 4 & $0,14 \%$ \\
\hline Trismo & 4 & $0,14 \%$ \\
\hline Fratura de processo alveolar & 2 & $0,07 \%$ \\
\hline Aftas pós-cirúrgicas & 2 & $0,07 \%$ \\
\hline Fratura de dente adjacente & 1 & $0,03 \%$ \\
\hline Deiscência de sutura & 1 & $0,03 \%$ \\
\hline Infecção do leito doador & 1 & $0,03 \%$ \\
\hline \multicolumn{3}{|l|}{ Introdução de raíz no seio } \\
\hline maxilar & 1 & $0,03 \%$ \\
\hline Lesão de comissura labial & 1 & $0,03 \%$ \\
\hline Periostite & 1 & $0,03 \%$ \\
\hline Úlcera por anestésico & 1 & $0,03 \%$ \\
\hline Fratura de ápice radicular & 1 & $0,03 \%$ \\
\hline Sinusite & 1 & $0,03 \%$ \\
\hline Total & 94 & $3,26 \%$ \\
\hline
\end{tabular}

Em relação às questões respondidas durante a anamnese, 2288 pacientes $(79,6 \%)$ responderam afirmativamente a pelo menos uma. A distribuição de respostas afirmativas segundo 0 tipo de alteração identificada, está apresentada na tabela 5. 
Tabela 5 - Distribuição numérica de respostas afirmativas, segundo tipo de alteração de saúde

\begin{tabular}{ll}
\hline Alterações ou situações de interesse & Respostas afirmativas \\
\hline Histórico de hemorragia & 105 \\
\hline Alergia & 600 \\
\hline Reumatismo infeccioso & 103 \\
\hline Distúrbio cardiovascular & 261 \\
\hline Gastrite ou úlcera & 412 \\
\hline Diabetes & 751 \\
\hline Desmaio & 457 \\
\hline Tratamento médico & 615 \\
\hline Medicamento & 968 \\
\hline Cirurgia ou internação recente & 647 \\
\hline Vícios & 740 \\
\hline Gravidez & 7 \\
\hline
\end{tabular}

Nas figuras 14, 15, 16 e 17, podemos observar com maior detalhe algumas questões. 


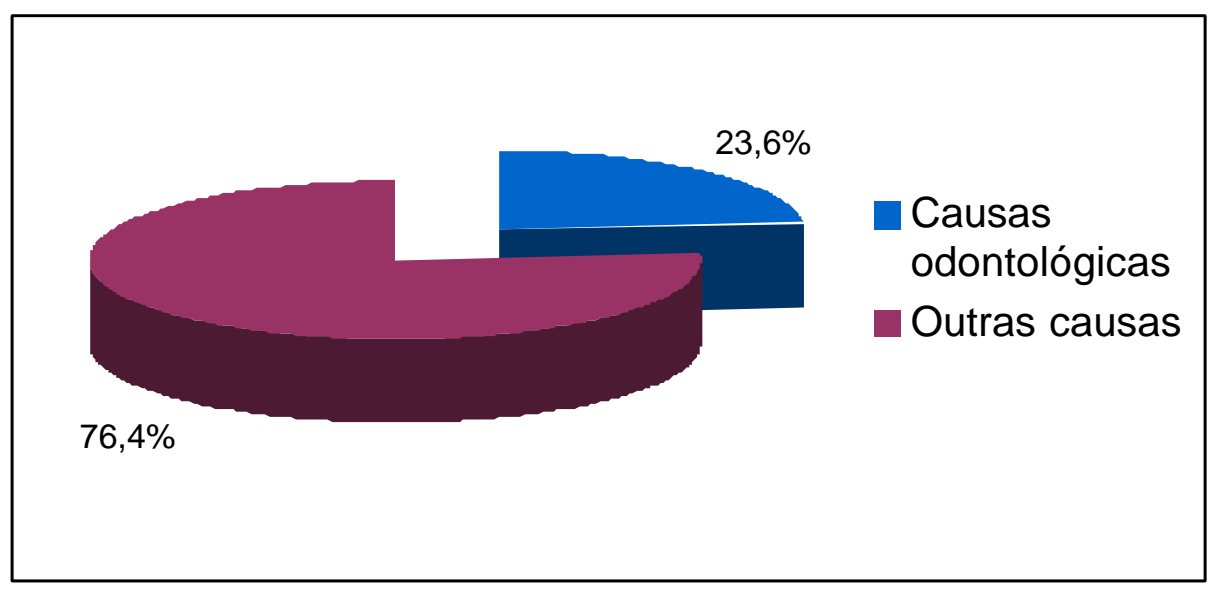

Figura 14 - Distribuição percentual de causas de hemorragias.

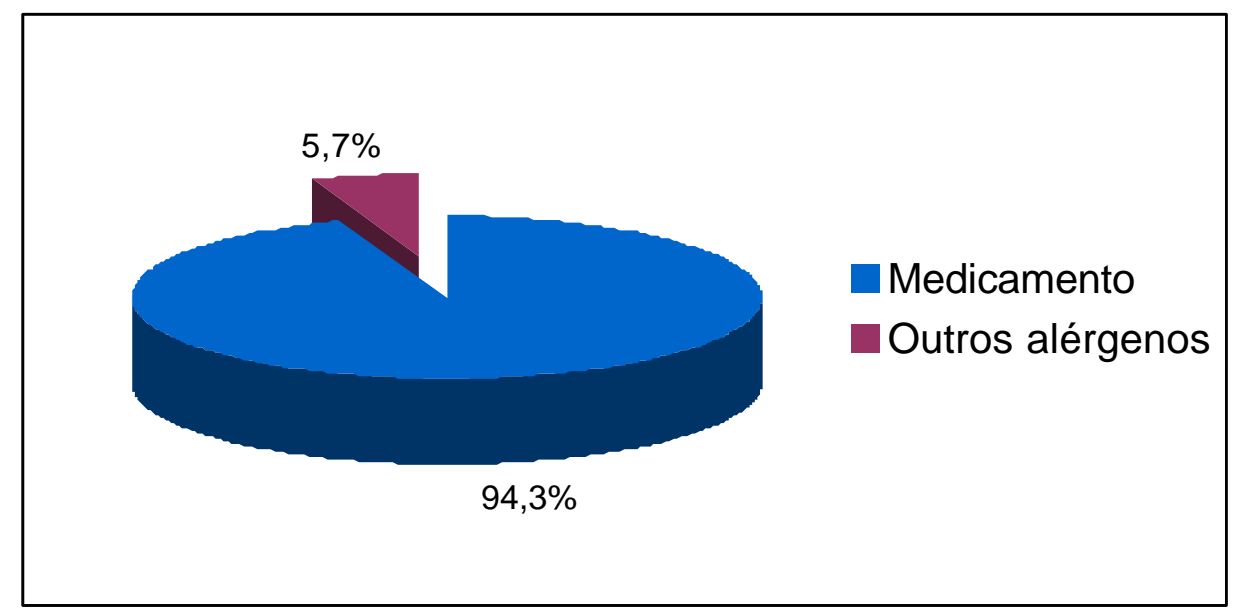

Figura 15 - Distribuição percentual das causas de alergia. 


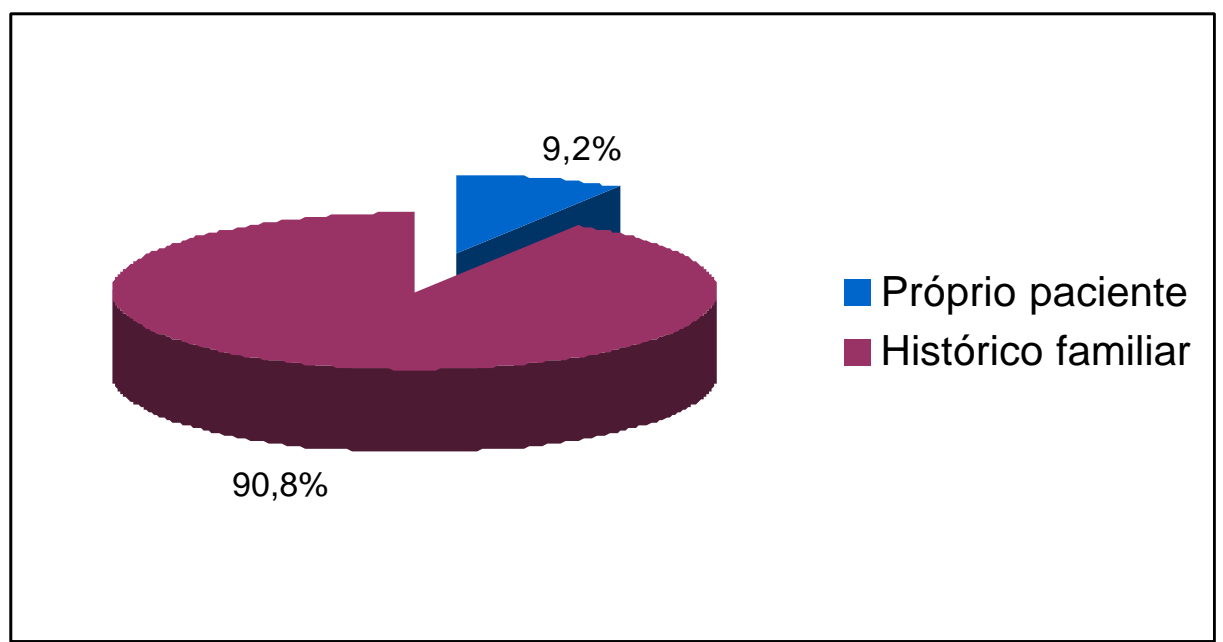

Figura 16 - Distribuição percentual de pacientes diabéticos ou com histórico familiar.

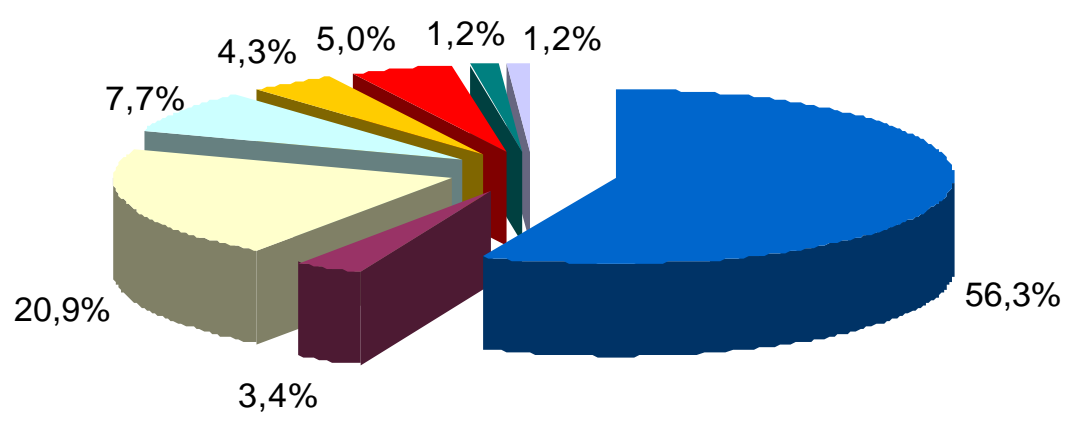

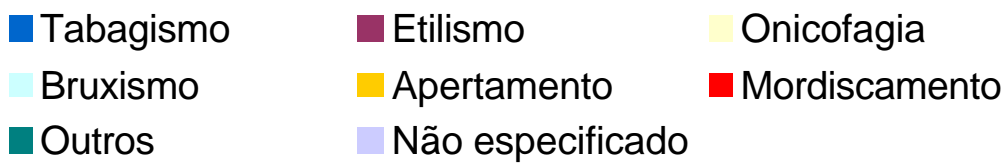

Figura 17 - Distribuição percentual dos vícios, hábitos ou manias relatados.

Foram identificados 1914 prontuários onde constavam os registros da aferição da pressão sanguínea realizada durante o exame clínico do paciente. Ficou constatada a presença da alteração do nível de pressão sanguínea em 535 pacientes (27,95\%). 
Destes pacientes hipertensos, observou-se que houve resposta negativa quando questionados sobre alterações cardiovasculares conforme distribuição apresentada na figura 18.

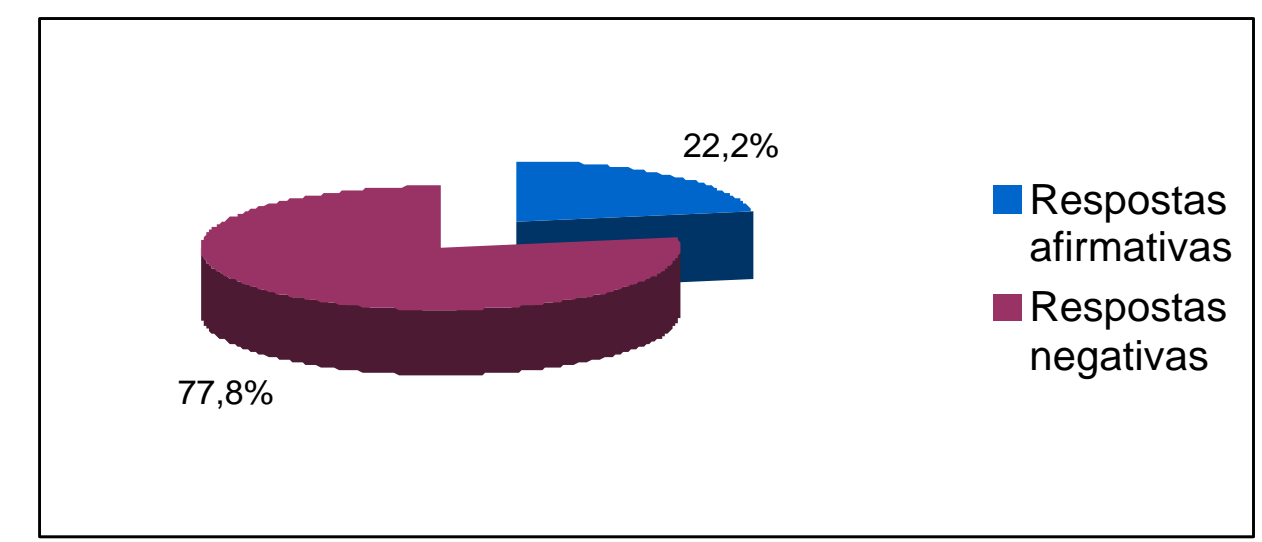

Figura 18 - Distribuição percentual entre respostas afirmativas e negativas a respeito de alterações cardiovasculares em pacientes hipertensos.

Como visto anteriormente, a exodontia foi o procedimento mais executado, resultando na extração de 8471 dentes, com uma média de 3,59 dentes extraídos por paciente.

Nestes prontuários foram identificadas as indicações para exodontia dos 8471 dentes extraídos (73,73\%) e para 3018 dentes observados em radiografias (26,27\%). Destes 11489 dentes, 11405 eram permanentes e 84 decíduos.

As indicações para os dentes decíduos e permanentes estão expostas na tabelas 6 e 7 . 
Tabela 6 - Prevalência das indicações para exodontia dos dentes decíduos

\begin{tabular}{lcc}
\hline Indicações para exodontia & Número de dentes & Porcentagem \\
Persistência do dente decíduo & 74 & $88,10 \%$ \\
\hline Indicação ortodôntica & 9 & $10,71 \%$ \\
\hline Cárie & 1 & $1,19 \%$ \\
\hline Total & 84 & $100,00 \%$ \\
\hline
\end{tabular}

Tabela 7 - Prevalência das indicações para exodontia dos dentes permanentes

\begin{tabular}{lcc}
\hline Indicações para exodontia & Número de dentes & Porcentagem \\
\hline Dente não irrompido & 2968 & $26,02 \%$ \\
\hline Cárie & 2409 & $21,12 \%$ \\
\hline Doença periodontal & 1967 & $17,25 \%$ \\
\hline Pericoronarite & 1924 & $16,87 \%$ \\
\hline Outras causas & 1168 & $10,24 \%$ \\
\hline Indicação ortodôntica & 463 & $4,06 \%$ \\
\hline Indicação protética & 295 & $2,58 \%$ \\
\hline Dente supranumerário & 170 & $1,50 \%$ \\
\hline Traumatismo dentário & 29 & $0,25 \%$ \\
\hline Perfuração endodôntica & 12 & $0,10 \%$ \\
\hline Total & 11405 & $100,00 \%$ \\
\hline
\end{tabular}

Analisando as indicações segundo a faixa etária observou-se a distribuição apresentada na tabela 8. 


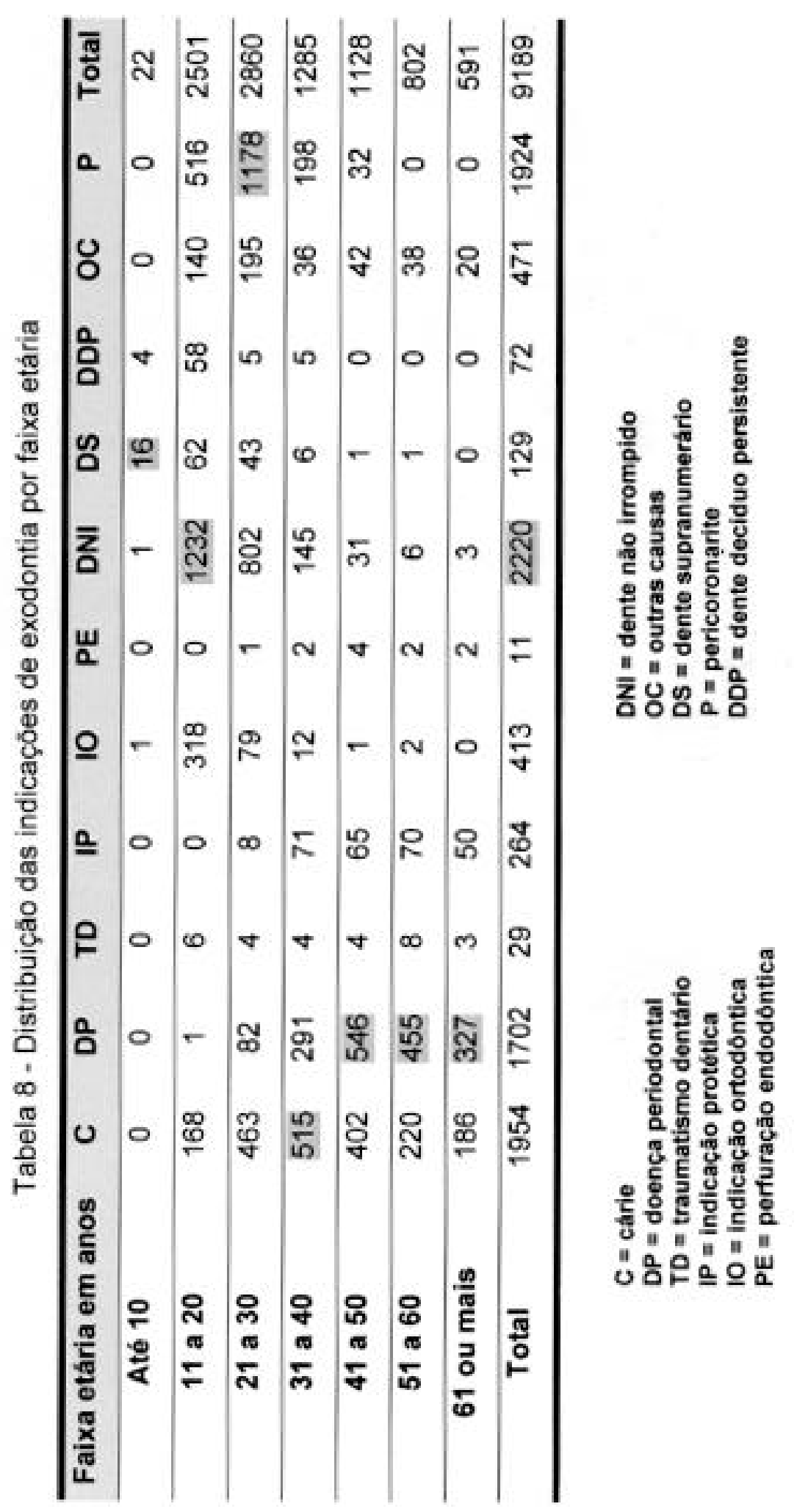


Os terceiros molares, quando observados, foram classificados de acordo com os critérios de PELL; GREGORY50 e WINTER ${ }^{69}$. Os 7222 terceiros molares observados nos prontuários de 2290 pacientes tiveram a distribuição apresentada nas tabelas 9 e 10.

Tabela 9 - Distribuição dos terceiros molares segundo classificação de PELL; GREGORY50

\begin{tabular}{|c|c|c|c|c|c|}
\hline \multirow{2}{*}{ Posição } & \multicolumn{4}{|c|}{ Dentes } & \multirow{2}{*}{ Total } \\
\hline & 18 & 28 & 38 & 48 & \\
\hline$A$ & 1017 & 1022 & - & - & 2039 \\
\hline$B$ & 365 & 362 & - & - & 727 \\
\hline $\mathrm{C}$ & 456 & 478 & - & - & 934 \\
\hline IA & - & - & 447 & 464 & 911 \\
\hline $\mathrm{IB}$ & - & - & 17 & 13 & 30 \\
\hline $\mathrm{IC}$ & - & - & 4 & 3 & 7 \\
\hline IIA & - & - & 686 & 667 & 1353 \\
\hline IIB & - & - & 495 & 476 & 971 \\
\hline $\mathrm{IIC}$ & - & - & 35 & 36 & 71 \\
\hline IIIA & - & - & 13 & 9 & 22 \\
\hline IIIB & - & - & 40 & 32 & 72 \\
\hline IIIC & - & - & 42 & 43 & 85 \\
\hline Total & 1856 & 1890 & 1817 & 1791 & 7222 \\
\hline
\end{tabular}


Tabela 10 - Distribuição dos terceiros molares segundo classificação de WINTER ${ }^{69}$

\begin{tabular}{|c|c|c|c|c|c|}
\hline \multirow{2}{*}{ Posição } & \multicolumn{4}{|c|}{ Dentes } & \multirow{2}{*}{ Tota } \\
\hline & 18 & 28 & 38 & 48 & \\
\hline Vertical & 1372 & 1347 & 977 & 925 & 4621 \\
\hline Mesioangulado & 133 & 141 & 549 & 557 & 1380 \\
\hline Distoangulado & 323 & 366 & 106 & 99 & 894 \\
\hline Horizontal & 4 & 3 & 123 & 147 & 277 \\
\hline Invertido & 3 & 1 & 12 & 11 & 27 \\
\hline Transalveolar & 3 & 4 & 12 & 4 & 23 \\
\hline Total & 1856 & 1890 & 1817 & 1791 & 7222 \\
\hline
\end{tabular}




\section{DISCUSSÃO}

\subsection{Gênero, idade e procedência dos pacientes}

Pela análise da figura 11, é possível observar que 1396 (38,9\%) prontuários de pacientes atendidos foram do gênero masculino e 2192 $(61,1 \%)$ do gênero feminino. A maior procura por atendimento de saúde por pacientes do gênero feminino é uma tendência observada também em outros estudos de mesma natureza ${ }^{7,12,24,41,45}$. Este fato é geralmente justificado por uma maior preocupação por parte das mulheres em relação à saúde ${ }^{12}$. No entanto, é necessário levar-se em conta que algumas indicações para exodontia são oriundas de processos agudos e dolorosos, como cárie, doença periodontal, pericoronarite, levando o paciente à procura de atendimento independentemente da relevância que a saúde bucal possa ter para este paciente, podendo esta característica influenciar a distribuição da população de estudo.

Após a verificação da idade presente nos prontuários de 2875 pacientes, foi possível determinar que a idade média dos pacientes atendidos nas clínicas de Cirurgia da FOB-USP foi de 31,3 anos. Este resultado foi semelhante ao encontrado por MOREIRA et al. ${ }^{41}$. Ao se analisar a distribuição dos pacientes segundo a faixa etária, observourse que a maior freqüência de atendimento foi para pacientes entre 21 e 30 anos de idade, com o total de 900 (31,3\%) indivíduos atendidos. Quando somados os pacientes com idades entre 11 e 30 anos, nota-se que estes totalizam 59,2\% dos atendimentos, percentual semelhante ao encontrado para pacientes com 30 anos ou menos (59,9\%). Este resultado é semelhante aos obtidos nos estudos de FERREIRA JÚNIOR ${ }^{12}$, McCAUL; JENKINS; KAY ${ }^{37}$, ONG; YEO; BHOLE $^{48}$ e PÁDUA ${ }^{49}$. No presente estudo o fato do maior número de indivíduos atendidos apresentarem idades entre 11 e 30 anos pode ser 
explicado pela principal indicação de exodontia, ou seja, a presença de dente não irrompido. É justamente nesta faixa etária que se localiza o período recomendado para a realização destas exodontias ${ }^{5,18,35,61}$.

Observamos ainda que não há uma padronização da estratificação por faixas etárias utilizadas em estudos desta natureza, o que dificulta comparações mais precisas dos dados $5,18,35,37,48,49,61$.

Analisando a procedência dos pacientes atendidos nas clínicas da Disciplina de Cirurgia da FOB-USP, constatourse que Bauru foi o município mais beneficiado pelos serviços prestados, com um total de 2301 (79,78\%) dos 2884 indivíduos com municípios de origem identificados. Este dado é explicado pela proximidade geográfica e facilidade de acesso dos indivíduos que necessitam de tratamento. Porém, nota-se a grande quantidade de municípios (108), tanto do estado de São Paulo quanto nos demais estados da federação, cujos moradores foram atendidos nas clínicas de Cirurgia da FOB-USP. Certamente a posição de destaque da Faculdade de Odontologia de Bauru como centro de excelência em odontologia favorece o fluxo de pacientes que aqui procuram tratamento.

Ainda sobre a procedência dos pacientes do município de Bauru $\mathrm{SP}$, na tabela 2 observa-se que a maioria dos pacientes é proveniente das regiões norte $(27,9 \%)$ e oeste $(29,6 \%)$, e que juntas totalizaram a maioria dos indivíduos atendidos (57,5\%). Este resultado é muito semelhante ao encontrado por FERREIRA JÚNIOR ${ }^{12}$, que justifica esta distribuição afirmando que estas são as regiões mais populosas do município, e acolhem, em sua periferia, população de baixa renda.

\subsection{Procedimentos realizados}

Em relação aos procedimentos realizados, o primeiro ponto que deve ser destacado é que $67,39 \%$ dos pacientes realizaram os exames 
radiográficos necessários ao planejamento cirúrgico na própria FOB-USP. O fato de as radiografias serem realizadas em sua maior parte nas clínicas da Disciplina de Radiologia permite certa padronização e controle de qualidade das mesmas, facilitando o planejamento cirúrgico.

Em 2886 prontuários foi possível determinar os procedimentos aos quais os pacientes foram submetidos. Ao se analisar a tabela 3 é possível observar 2359 exodontias realizadas, e somente 571 outros tipos de procedimentos. Isto pode passar a imagem de que se prefere a exodontia a outros procedimentos, contudo, deve ser ressaltado que a Disciplina de Cirurgia da FOB-USP é partidária e defensora de uma filosofia conservadora, atualmente assumida pela Odontologia ${ }^{21,36}$, e adota uma postura criteriosa com relação à indicação de exodontia, principalmente pela irreversibilidade do procedimento. Somando-se este aspecto à maior concentração de pacientes adultos jovens atendidos, é possível vislumbrar a importância da decisão de indicar a exodontia com embasamento científico fundamentado em conhecimentos atualizados, uma vez que os resultados e conseqüências deste procedimento acompanharão o indivíduo pelo resto da vida $^{12,21,36,53}$.

Em estudos realizados com a finalidade de se verificar os procedimentos odontológicos realizados numa determinada população, é possível observar que a exodontia não é o procedimento mais realizado, como demonstram BRENNAN; SPENCER; SZUSTER ${ }^{7}$ e FERREIRA JÚNIOR $^{12}$. No entanto, é compreensível que este procedimento tenha sido o mais realizado neste estudo, uma vez que o atendimento dos pacientes na FOB-USP é realizado por clínicas específicas de cada disciplina, e por isso os casos onde há necessidade de exodontias são encaminhados para as clínicas da Disciplina de Cirurgia. Para determinação do real papel da exodontia no atendimento de pacientes em toda a FOB-USP, serão necessários estudos epidemiológicos envolvendo as demais disciplinas e com certeza terá um percentual muito baixo. 
Observa-se ainda a execução de procedimentos não rotineiros para estas clínicas, como a realização de biópsia em 124 pacientes, sendo este procedimento comumente realizado nas clínicas da Disciplina de Estomatologia. A baixa complexidade deste procedimento, associada muitas vezes à necessidade de confirmação do diagnóstico de patologias abordadas em outros procedimentos, justifica a realização do mesmo.

Por receber pacientes atendidos nas clínicas das demais disciplinas da Faculdade de Odontologia de Bauru, é compreensível o número de procedimentos cirúrgicos com finalidade ortodôntica, com o atendimento de 39 pacientes onde foram realizadas cirurgias para colagem de acessório para tracionamento ou disjunção cirurgicamente guiada da maxila, ou protéticas, com a realização de 73 procedimentos como instalação de implantes, cirurgias avançadas para implante ou outras cirurgias pré-protéticas. É importante ressaltar que as cirurgias em implantodontia foram recentemente incorporadas ao rol de procedimentos realizados pelas clínicas de Cirurgia, e necessitarão de novos estudos a fim de verificar a possibilidade de uma participação maior na distribuição dos procedimentos realizados futuramente.

\section{3 - $\underline{\text { Acidentes e complicações }}$}

MARZOLA $^{36}$ diferencia acidente de complicação, afirmando que o primeiro ocorre durante a execução do ato drúrgico e a segunda situação depois de finalizado tal ato. A literatura demonstra que estas situações eram mais freqüentes nos procedimentos realizados num passado não muito remoto da Odontologia ${ }^{36}$ e houve um declínio em suas ocorrências devido aos avanços das técnicas, materiais e instrumentos utilizados durante a intervenção cirúrgica. Isto também é atribuído a maior observância dos cuidados preventivos, expressos principalmente pela realização de exame clínico minucioso e modernos exames complementares ${ }^{11,26,30,36,62}$. Nos 
prontuários analisados foram constadas 94 ocorrências de acidentes ou complicações em 92 pacientes, correspondendo a 3,18\% dos pacientes atendidos.

A complicação mais freqüente foi a alveolite ocorrida em 28 pacientes, acometendo $0,97 \%$ dos pacientes. Este resultado é inferior aos $3,22 \%$ relatados no estudo de PÁDUA ${ }^{49}$ e aos $5 \%$ relatados por MALDEN; MAIDMENT ${ }^{33}$. Esta é a complicação mais freqüentemente observada após exodontias ${ }^{8,25,49,56}$, sendo relatas prevalências que variam de 0,5 a $68,4 \%$ no estudo de HOUSTON ${ }^{25}$, de 1 a $30 \%$ num workshop sobre terceiros molares ${ }^{56}$ e no estudo de MOGHADAM; CAMINITI ${ }^{40}$. De forma geral as alveolites ocorrem numa faixa de 1 a $3 \%$ das exodontias ${ }^{49}$.

Esta complicação apresenta etiologia multifatorial e ainda necessita ser totalmente elucidada. $\mathrm{O}$ que se sabe é que está associada à má higiene bucal, traumatismo cirúrgico, etilismo, tabagismo, uso de contraceptivos e aumento da atividade fibrinolítica ${ }^{25,49}$. O gênero feminino é o mais afetado ${ }^{25,49}$, fato este justificado por interações hormonais, ainda mais freqüente quando a paciente faz uso de contraceptivos orais ${ }^{25}$.

Hemorragias, tanto durante quanto após o procedimento cirúrgico, têm sido relatadas em diferentes estudos com freqüências que variam de 7 a $10 \%$ para exodontias de terceiros molares ${ }^{40}$, e de 0,2 a $1,4 \%$ de forma geral ${ }^{56}$. Na população de estudo foi relatada hemorragia em $0,76 \%$ dos pacientes atendidos, demonstrando concordância com os resultados de outros estudos $8,33,40,56$

Os demais acidentes ou complicações, como parestesia, fratura de túber ou comunicações bucossinusais, apresentaram prevalências semelhantes às descritas na literatura ${ }^{8,56}$. 


\subsection{Exame clínico}

Conforme destacado por diversos autores em diferentes estudos 11,21,26,30,36,53,56,62, o exame clínico é de inconteste importância não somente na determinação do plano de tratamento, mas também no reconhecimento do quadro de saúde geral do paciente, permitindo a adoção de condutas preventivas com vistas à diminuição de riscos específicos frente 0 reconhecimento de alguma alteração de ordem sistêmica ou local 11,21,26,30,36,53,56,62. Durante o exame clínico o cirurgião-dentista coleta dados e informações, por meio de questionários ou aferição direta, para avaliação do impacto dos procedimentos a serem realizados na saúde deste paciente, permitindo assim a avaliação dos riscos e a determinação da melhor oportunidade para realização das intervenções. No presente estudo, dois componentes do exame clínico (a anamnese e a aferição da pressão sangüínea) forneceram as informações quanto à presença de alterações do estado de saúde geral do paciente.

Foi possível determinar que, dos 2886 pacientes que responderam às questões contidas na anamnese das fichas clínicas, 2288 responderam afirmativamente a pelo menos uma das questões, indicando que $79,3 \%$ poderiam apresentar alguma alteração de saúde relevante para o tratamento. Porém, é inegável o fato de, por se tratar de um questionário com respostas livres, um certo número de respostas afirmativas não apresenta vam qualquer relevância para o atendimento destes pacientes.

A questão que apresentou maior número de respostas afirmativas (968) foi relativa ao uso de medicamento, ou seja, 17,1\% das respostas afirmativas. Ao compararmos este número ao número de respostas afirmativas em relação ao tratamento ou acompanhamento médico, observou-se que 615 pacientes (10,8\%) responderam afirmativamente a esta última. Sugere isto que 353 pacientes que fazem uso de algum medicamento o fazem sem orientação de médica, ou seja, que $36,5 \%$ dos 
pacientes se automedicam. Ainda sobre o uso de medicamentos, é importante salientar que algumas patologias podem ser identificadas pelo fármaco em uso e ainda mais importante, é a avaliação da possível interação deste medicamento com outros a serem ministrados (anestésicos, antibióticos e analgésicos, por exemplo), ou a influência destes medicamentos em alguns processos biológicos importantes, como cicatrização e coagulação ${ }^{11,26,62}$, principalmente em procedimentos cirúrgicos.

Dos 105 relatos de hemorragia, 25 (23,6\%) possuíram causas odontológicas e as demais relacionadas a outros fatores.

Em relação à questão sobre alergias, ou hipersensibilidades, 600 $(20,8 \%)$ dos 2886 pacientes responderam afirmativamente. Esta é uma alteração importante e pode modificar o uso de substâncias químicas, principalmente sob a forma de soluções, no atendimento deste paciente. Sobre os alérgenos, observou-se que $94,3 \%$ das causas relatadas eram componentes de soluções, como água oxigenada ou iodo, ou medicamentos de uso odontológico, como penicilinas, eritromicina, ácido acetilsalicílico e dipirona.

O diabetes é uma doença sistêmica importante por ser considerada um dos principais fatores predisponentes de doenças cardíacas e pelo aumento na sua incidência atualmente ${ }^{13,26,39}$. Está associada a várias outras alterações importantes, como doença vascular aterosclerótica e alterações na vascularização periférica, apresenta uma evolução "silenciosa", assintomática, mas que pode levar a óbito por suas complicações ${ }^{13,26,39}$. Envolve ainda uma série de alterações odontológicas, expressas principalmente por acometimento periodontal ${ }^{65}$ e por maior susceptibilidade a infecções e deficiência no processo de reparo ${ }^{31,36}$. 
Sua prevalência na população adulta é de $7,6 \%{ }^{39}$, sendo superior ao constatado neste estudo, onde a prevalência foi de $2,32 \%$ para os 2886 pacientes atendidos, ou seja, 67 pacientes diabéticos. Embora tenha figurado como segunda maior causa de respostas afirmativas, nota-se que apenas $9,2 \%$ afirmavam ser eles os diabéticos e que $90,8 \%$ das respostas era em decorrência de histórico familiar.

Outra doença crônica de notória importância é a hipertensão arterial, que é fortemente associada a outras doenças cardiovasculares. Atualmente estas doenças são as responsáveis por $27,4 \%$ das mortes no Brasil $^{39}$. A hipertensão arterial está associada ao acidente vascular cerebral em $80 \%$ dos casos e à doença isquêmica do coração em $60 \%{ }^{39}$. Assim como o diabetes, acomete indistintamente a população brasileira, assumindo proporções de problema de saúde pública ${ }^{35,39,66}$.Sua prevalência, segundo o Ministério da Saúde ${ }^{39}$ é de 11 a $20 \%$ da população acima dos 20 anos de idade.

No presente estudo, foi observada uma porcentagem de 9,08\% de respostas afirmativas quanto a distúrbios cardiovasculares. Especificamente para hipertensão arterial, foram observados 119 relatos que correspondem a $4,12 \%$ dos 2886 pacientes que responderam ao questionário da anamnese. Este percentual estava ainda sujeito a omissões, voluntárias ou não, da real condição dos pacientes. Com a finalidade de verificação, aplicamos os critérios do JNC dos níveis pressóricos para determinação de hipertensão arterial, aos prontuários onde estavam presentes as anotações destes níveis, aferidos no exame clínico. Contudo observourse um fato indesejável para o atendimento seguro dos pacientes, uma vez que dos 2886 prontuários examinados, somente em 1914 (66,32\%) foram anotados os valores da aferição da pressão sangüínea. Este dado sugere que os cirurgiões-dentistas subestimam este procedimento, não atendendo às condutas esperadas ${ }^{11,30,62}$. Verificou-se que de um total de 1914, 535 eram de pacientes hipertensos $(27,95 \%)$. 
Confrontando este dado às 119 respostas sobre a existência de alteração cardiovascular pôde-se determinar que destes 535 pacientes, 416 $(77,76 \%)$ responderam negativamente quanto ao fato de serem hipertensos, embora apresentassem níveis pressóricos elevados, conforme distribuição observada na figura 18. Este resultado alerta para o fato da possível presença de alterações cardiovasculares mesmo quando 0 paciente desconhece sua real condição. No presente estudo, a freqüência de pacientes hipertensos que omitiram o fato foi de $21,73 \%$. No estudo de LOPES; NASCIMENTO ${ }^{31}$, a prevalência foi de $6,2 \%$. Os pacientes hipertensos (535) corresponderam a $18,53 \%$ dos 2886 pacientes atendidos. Assim, observoutse que a prevalência da hipertensão arterial em nosso estudo foi semelhante ao determinado pelo Ministério da Saúde ${ }^{39}$.

A OMS considera valores iguais ou maiores que $160 \mathrm{~mm} / \mathrm{Hg}$ e $95 \mathrm{~mm} / \mathrm{Hg}$ para as pressões sistólica e diastólica, respectivamente ${ }^{35,66}$. No entanto, o critério proposto pelo JNC, em que se considera hipertensão arterial níveis pressóricos iguais ou superiores a $140 \mathrm{~mm} / \mathrm{Hg}$ e $90 \mathrm{~mm} / \mathrm{Hg}$ para pressão arterial sistólica e diastólica, respectivamente, é o adotado atualmente pelo Ministério da Saúde ${ }^{39}$. Por esta razão, neste estudo foi adotado somente o critério proposto pelo JNC para a determinação dos pacientes hipertensos por aferição direta da pressão sangüínea.

\subsection{Indicações para exodontias}

Os resultados relativos às exodontias realizadas demonstraram um total de 8471 dentes extraídos nas clínicas da Disciplina de Cirurgia da FOB-USP, com uma média de 3,59 dentes extraídos por paciente. Este resultado é superior ao obtido por MURRAY; CLARKE; LOCKER ${ }^{43}$, que obtiveram uma média de 2,4 dentes extraídos por paciente, por McCAUL; JENKINS; KAY ${ }^{37}$, com média de 1,5 dente extraído, e por ONG; YEO; 
BHOLE $^{48}$, com média de 1,7 dente. No estudo de GABRE; MARTINSSON; GAHNBERG ${ }^{15}$, embora a média tenha sido maior (3,72 dentes por paciente), é necessário salientar que o estudo envolveu população de pacientes deficientes mentais e por isso mais propensos a alterações que levassem a perdas dentárias.

Ao avaliar a indicação de exodontia, consideraram-se os dentes efetivamente extraídos nas clínicas da Disciplina de Cirurgia da FOB-USP (8471) e aqueles que poderiam ser extraídos em oportunidade futura nestas clínicas (3018). Não foram levados em conta os dentes ausentes ou o histórico de exodontias, realizadas em qualquer outro serviço de atendimento odontológico, uma vez que havia o interesse de avaliar os procedimentos realizados pela Disciplina de Cirurgia. Pode-se classificar as causas determinantes de exodontia de 11489 dentes, e destes 11405 $(99,27 \%)$ eram permanentes e apenas 84 (0,73\%) eram decíduos. Esta diferença provavelmente ocorre pelo processo evolutivo normal da dentição humana, onde os dentes decíduos, depois de decorrido um período normal de permanência na boca e quando se inicia o irrompimento dos permanentes, esfoliam-se e naturalmente são substituídos.

Dos 11405 dentes com indicação para exodontia, observourse que 2968 (26,02\%) apresentavam-se não irrompidos e com discrepância entre o espaço disponível e o espaço necessário para seu correto irrompimento. A literatura acerca do assunto destaca a incongruência a respeito da necessidade de exodontia de dentes não irrompidos assintomáticos, representados em sua maioria por terceiros molares $5,6,18,27,56,58$. É possível observar argumentação sobre os prós e contras da indicação de exodontia de tais dentes, sem se chegar a um censo comum de como proceder na avaliação da necessidade da extração. Seria extremamente fácil acumular artigos sobre estudos que conduzissem a uma conclusão favorável ou desfavorável sobre esta indicação, se esta fosse a intenção de quem pesquisa. Contudo uma análise criteriosa fatalmente culminará nas 
seguintes conclusões: este assunto necessita estudos mais aprofundados para que se possa chegar a um consenso; várias são as situações que justificam a exodontia de um dente não irrompido assintomático, como por exemplo, a necessidade de movimentos distais dos primeiros e segundos molares, presença de lesões associadas a este dente (cistos, neoplasias) e a possibilidade de reabsorção do próprio dente ou dentes adjacentes. Quando se optar pela exodontia esta apresentará melhores resultados se realizadas em adulto jovens ${ }^{5,18,27}$. Ainda sobre as situações que justificam a indicação e realização de exodontia dos terceiros molares, destacam-se duas comumente observadas durante este estudo: a reabsorção de raízes dos segundos molares, e a falta de espaço para correto irrompimento $5,6,18,71$.

Outro fator que pode ter interferido na maior concentração de indicações para exodontia dos dentes não irrompidos, é o declínio da incidência da cárie nos últimos anos e também de sua severidade, tornando o tratamento de suas seqüelas cada vez mais embasado em restaurações que em extrações ${ }^{2,14,20,44,52,59,66}$. Contudo, não justificaria totalmente a maior prevalência de indicação de dentes não irrompidos, podendo sugerir que a realização de exodontia destes dentes sem nenhum custo para o paciente possa ter influência na distribuição das indicações, pela maior procura das clínicas de Cirurgia quando da necessidade de realização ou para avaliação desta necessidade.

A cárie ocupa a segunda posição nas indicações das exodontias, com 2409 dentes, e a doença periodontal a terceira com 1976. Na literatura estas causas figuram geralmente como as maiores indicações de exodontia $7,10,15,22,23,24,36,37,41,42,43,45,48,55$, condição esta não observada somente em estudos com populações alvo ou condições específicas ${ }^{34,47}$. Este estudo apresenta uma distribuição atípica quando comparado aos demais, possivelmente por ter sido desenvolvido num serviço de atendimento com população, interesses didáticos e características próprias. 
Ao analisar a distribuição das causas segundo faixas etárias, foi possível observar um maior número de indicações de exodontia para dentes supranumerários (16) em pacientes com dez anos ou menos, dentes não irrompidos (1232) em pacientes de 11 a 20 anos, pericoronarite (1178) para os entre 21 e 30 anos, cárie (515) dos 31 aos 40, e doença periodontal (1328) acima dos 41 anos. Esta distribuição pode ser justificada pela já citada diminuição do número de cáries na população infantil 2,14,20,44,52,59,66, favorecendo a evolução normal da dentição humana, exigindo intervenções apenas nos quadros anômalos desta dentição, como dentes supranumerários nos pacientes mais jovens, dentes não irrompidos mal posicionados durante a adolescência e os transtornos do irrompimento incorreto destes dentes em pacientes adultos jovens.

\subsection{Posição dos terceiros molares}

A classificação dos terceiros molares, de acordo com sua posição, tem a finalidade de auxiliar o planejamento cirúrgico, pois, de certa forma, determina a complexidade do caso ${ }^{53,61}$. Entretanto, GARCIA ${ }^{16}$ não observou correlação entre o nível de complexidade do caso e a classificação proposta por PELL; GREGORY50.

As classificações dos terceiros molares não irrompidos têm sido utilizadas também para prever a possibilidade de irrompimento destes dentes, e em relação a esta utilização, há uma certa controvérsia $5,18,35$. Quando estes dentes apresentam-se em posição angular desfavorável ao irrompimento, como horizontal, invertido ou transalveolar (segundo classificação de WINTER $^{69}$ ), certamente não apresentará condição para irrompimento mesmo com o passar do tempo. O mesmo raciocínio é válido para os dentes onde não há espaço suficiente no arco dentário para o seu posicionamento. As dúvidas surgirão quando o dente apresentar angulação satisfatória, porém permanece intra-ósseo. Os métodos para determinar se 
um dente não irrompido permanecerá nesta condição ou irá irromper após algum tempo, se mostraram ineficazes, imprecisos e não confiáveis ${ }^{5}$. 


\section{Conclusões}

A partir dos dados obtidos pode-se concluir que:

- Houve maior procura pelos serviços prestados pelas clínicas da Disciplina de Cirurgia da FOB - USP por pacientes do gênero feminino;

- A maior freqüência de indivíduos, segundo as faixas etárias, foi para os pacientes entre 21 e 30 anos;

- Mesmo tratando-se de clínicas de procedimentos cirúrgicos em odontologia, deve prevalecer uma filosofia conservadora, tendo em vista que a freqüência de indivíduos atendidos com idade inferior a 30 anos foi de $59,9 \%$;

- Bauru foi o município mais beneficiado pelos serviços das clínicas da Disciplina de Cirurgia da FOB-USP;

- O procedimento mais realizado foi a exodontia;

- Os índices de acidentes e complicações observados estão em níveis plenamente satisfatórios;

- A cárie e suas conseqüências não são a principal causa de atendimento nas clínicas da Disciplina de Cirurgia da FOB-USP, sendo a principal indicação para exodontia os dentes não irrompidos. 
ANEXOS 


\section{Anexo 1 - Modelo da ficha clínica utilizada}

UNIVERSIDADE DE SÁO PAULO
FACULDADE DE ODONTOLOGLA DE BAURU
CIINICA DE GIRURGIA

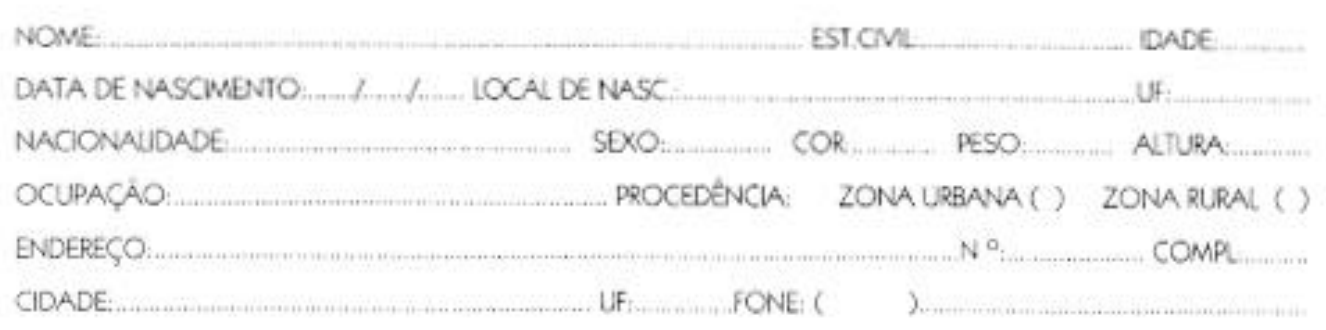

\section{AUIORZACÁO PARA DUAGNÓSTICO EOUU EXECUCÁO DE TRATAMENTO}

Pur este notumento de autcrzaçio por mim assinaco, dou pleno consentmento d FACUADADE OE ODCNIOLCGR DE BALLULUSP para, por ntermédio de seus professores, assstentes e aunOs devidamente autorizados, fazer dagnósico, planejamento e tratamento em minha pessca de acordo com os conhecinentos enquadrados no campo dessa especaldade

Concordo tamberm, que todas as radiografias, fotografis, modelos, desernos, histónicos de antecedentes familates, resultados de exame clinico e de lacoratório e quasquer outras informaçoes concementes as planejamento, dagnóstico e/ou tratamento, consutuem propriedade exclusiva desta FACULDADE, à qual dou pienos drettos de retençäo, uso para quaisquer fins de ensino e de dimulgaçao em jomais e/ou em revistas cientificas do pais e do estrangeiro, respeitando os respectvos códigos de ética.

Bouru ............ de . de

Assinatura do paciente ou respcrisavel

QUEXXA PRENGPA:

HISTORIA DA DOENCA ATUAL

\section{HISTORA MEDICA}

01. Já teve hemorragia?

02. Solre (u) de alerga ?

03. Teve reumatismo infeccioso?

04. Sofre (u) de disturbio carciovascular?

05. Sofre (u) de gastrite cu ilcera ?

06. E dabebico ou tem famiares diabétcos

07 . Ja desmaicu algums vez ?

0B. Está sob tratamento médico?

09. Estó tomando algum medicamento?

10. Esteve doente ou for operado nos ultimos 5 anos?

11. Tem hábios, vicios ou manias?

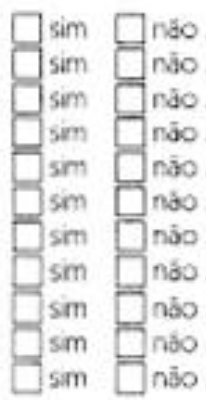


PLANO DE TRATAMENTO PARA EXODONTIAS

PRÉ-OPERATÓRIO
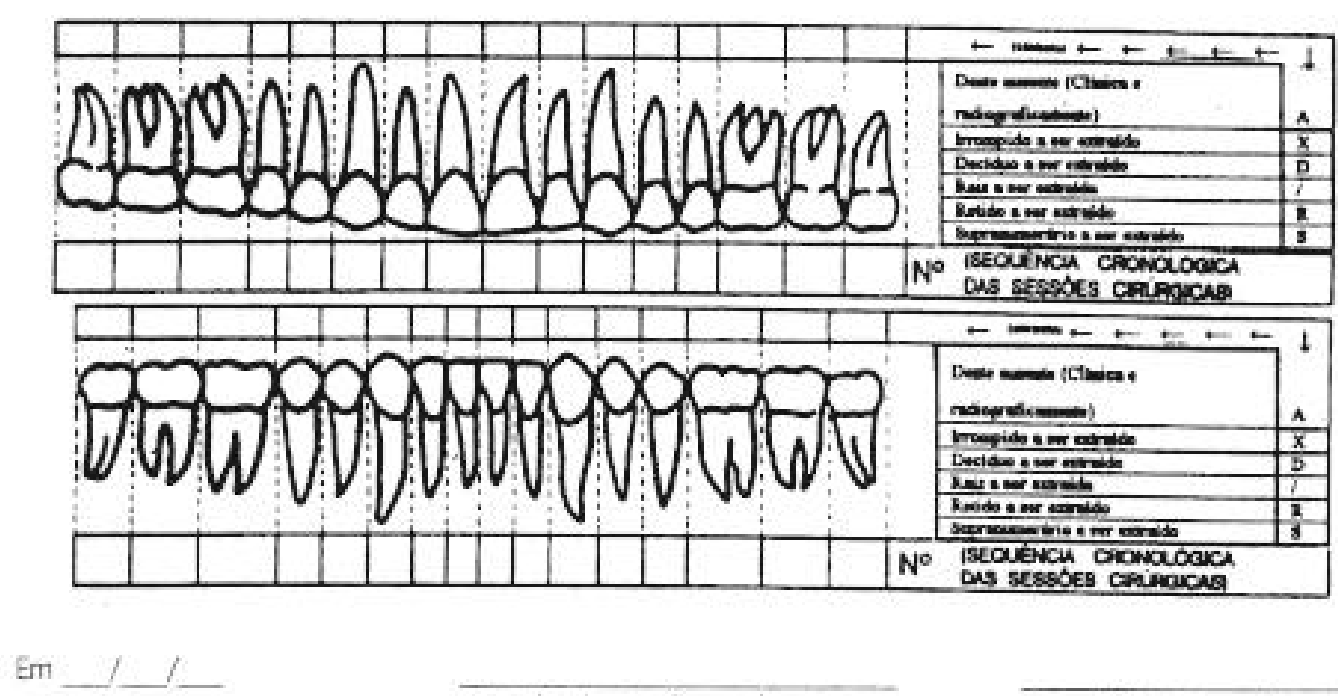

Ass. do aluno $0^{\circ}$ do ano

Visto do protessor

Ooservaçōes:

PLANO DE TRATAMENTO PARA OUTRAS CIRURGIAS

PRÉ-OPERATÓRIO

\begin{tabular}{|c|c|c|c|}
\hline \multicolumn{4}{|c|}{ CIRURGIAS } \\
\hline ALELOPLASTA & CURETAGEM & HIPERPUASA & OUTRAS CRUREIAS: \\
\hline APKECTOMLA & A) PERLAPICAL & REINPLANTE & \\
\hline BIOPSA & B) OUTRA & SULCOPLASTA & \\
\hline BRIDAS & DRENAGEM ABCESSO & TRANSPLANTE & \\
\hline CISTOS & A) INTRA-BUCAL & ULECTOMA & \\
\hline A) OESCOMPRESSÄO & B)EXTQA-BUCA & MPLANTES & \\
\hline B) ENUCLACAOO & FRENUIECTOMIA & A) DENTE & \\
\hline O) MAQSUPLALIVACД̄O & FRENULECTONAS & B) MATERIAS & \\
\hline COMLNCACÁO & FENULOPLASTIA & & \\
\hline
\end{tabular}

Em

Ass. do aluno $n^{\circ}$

do

ano

Vsto do professor

Observaçōes 
Anexo 2 - Distribuição dos pacientes por município de origem

\begin{tabular}{|c|c|}
\hline Municípios & Número de pacientes \\
\hline Águas de Santa Bárbara & 1 \\
\hline Agudos & 53 \\
\hline Americana & 1 \\
\hline Apucarana & 1 \\
\hline Araçatuba & 1 \\
\hline Arandu & 3 \\
\hline Aranduva & 1 \\
\hline Araraquara & 2 \\
\hline Araras & 1 \\
\hline Arealva & 23 \\
\hline Assis & 4 \\
\hline Avaí & 4 \\
\hline Avaré & 7 \\
\hline Bariri & 10 \\
\hline Barra Bonita & 5 \\
\hline Bauru & 2301 \\
\hline Bernardino de Campos & 2 \\
\hline Bocaina & 1 \\
\hline Bofete & 5 \\
\hline Boracéia & 3 \\
\hline Borebi & 6 \\
\hline Botucatu & 40 \\
\hline Brasília & 1 \\
\hline Brotas & 2 \\
\hline Cabrália Paulista & 7 \\
\hline
\end{tabular}




\begin{tabular}{|c|c|}
\hline Campinas & 2 \\
\hline Cândido Mota & 4 \\
\hline Cerqueira César & 4 \\
\hline Chavantes & 1 \\
\hline Conchas & 1 \\
\hline Curitiba & 3 \\
\hline Dois Córregos & 9 \\
\hline Duartina & 21 \\
\hline Espírito Santo do Turvo & 15 \\
\hline Franca & 1 \\
\hline Gália & 1 \\
\hline Garça & 3 \\
\hline Guaitina & 1 \\
\hline Hortolândia & 1 \\
\hline lacanga & 2 \\
\hline laras & 4 \\
\hline Ibitinga & 1 \\
\hline Igaraçu do Tietê & 6 \\
\hline Irapuã & 1 \\
\hline Itaí & 1 \\
\hline Itajaí & 1 \\
\hline Itajú & 1 \\
\hline Itapetininga & 1 \\
\hline Itápolis & 1 \\
\hline Itapuí & 2 \\
\hline Jaboticabal & 3 \\
\hline Jales & 1 \\
\hline Jaú & 11 \\
\hline Leme & 1 \\
\hline Lençóis Paulista & 53 \\
\hline
\end{tabular}




\begin{tabular}{|c|c|}
\hline Limeira & 1 \\
\hline Londrina & 1 \\
\hline Lucélia & 2 \\
\hline Lucianópolis & 6 \\
\hline Lutécia & 1 \\
\hline Macatuba & 5 \\
\hline Manaus & 1 \\
\hline Marília & 4 \\
\hline Maringá & 2 \\
\hline Matão & 1 \\
\hline Mineiros do Tietê & 2 \\
\hline Mogi Mirim & 1 \\
\hline Novo Horizonte & 25 \\
\hline Ourinhos & 8 \\
\hline Palmital & 4 \\
\hline Paraguaçu Paulista & 1 \\
\hline Paranapanema & 1 \\
\hline Paranavaí & 4 \\
\hline Pardinho & 1 \\
\hline Pederneiras & 21 \\
\hline Penápolis & 1 \\
\hline Pereiras & 1 \\
\hline Petrolina & 1 \\
\hline Piracicaba & 6 \\
\hline Piraju & 4 \\
\hline Pirajuí & 17 \\
\hline Pirassununga & 1 \\
\hline Piratininga & 33 \\
\hline Pompéia & 1 \\
\hline Pratânia & 1 \\
\hline
\end{tabular}




\begin{tabular}{lc} 
Presidente Alves & 13 \\
\hline Presidente Prudente & 2 \\
\hline Reginópolis & 5 \\
\hline Ribeirão Bonito & 1 \\
\hline Ribeirão Corrente & 2 \\
\hline Ribeirão do Sul & 1 \\
\hline Ribeirão Preto & 2 \\
\hline Rio Claro & 1 \\
\hline Santa Cruz & 1 \\
\hline Santa Cruz do Rio Pardo & 23 \\
\hline Santos & 1 \\
\hline São Bernardo do Campo & 1 \\
\hline São Carlos & 3 \\
\hline São José do Rio Preto & 2 \\
\hline São José dos Campos & 1 \\
\hline São Manuel & 12 \\
\hline São Paulo & 2 \\
\hline Sumaré & 2 \\
\hline Taquaritinga & 2 \\
\hline Taquarituba & 1 \\
\hline Tatuí & 3 \\
\hline Tibiriçá & 2884 \\
\hline Ubirajara & 1 \\
\hline Total & 2 \\
\hline & 2 \\
\hline
\end{tabular}


REFERÊNCIAS BIBLIOGRÁFICAS 


\section{Referências bibliográficas *}

1. ARAÚJO, R.B. et al. Avaliação do cuidado prestado a pacientes diabéticos em nível primário. Rev. Saúde públ., v.33, n.1, p.2432, fev. 1999.

2. ATHERTON, G.J.; McCAUL, J.A.; WILLIAMS, S.A. Medical emergencies in general dental practice in Great-Britain. Part 1: their prevalence over a 10-year period. Brit. dent. J., v.186, n.2, p.72-9, Jan. 1999.

3. BALDANI, M.H.; NARVAI, P.C.; ANTUNES, J.L.F. Cárie dentária e condições sócio-econômicas no Estado do Paraná, Brasil, 1996. Cadernos de Saúde Pública, v.18, n.3, p.755-63, mai./jun. 2002.

4. BARATA, R.C.B. O desafio das doenças emergentes e a revalorização da epidemiologia descritiva. Rev. Saúde públ., v.31, n.5, p.531-7, out. 1997.

5. BENOTTI, D.G. Avaliação da necessidade de exodontia de terceiros molares inferiores inclusos e/ou impactados. São Paulo, 2002. 136p. Dissertação (Mestrado) - Faculdade de Odontologia, Universidade de São Paulo.

6. BISHARA, S.E. Third Molars: A Dilemma! Or is it? Amer. J. Orthodont. Dentofac. Orthop., v.115, n.6, p.628-33, 1999.

7. BRENNAN, D.S.; SPENCER, A.J.; SZUSTER, F.S.P. Provision of extraction by main diagnosis. Int. dent. J., v.51, n.1, p.1-6, 2001.

* Normas recomendadas para uso no âmbito da Universidade de São Paulo, com base no documento "Referências Bibliográficas: exemplos", emanados do Conselho Supervisor do Sistema Integrado de Bibliotecas da USP, em reunião de 20 de setembro de 1990. 
8. CHIAPASCO, M.; CICCO, L. de; MARRONI, G. Side effects and complications associated with third molar surgery. Oral Surg. v.76, n.4, p.412-20, Oct. 1993.

9. COLUSSI, C.F.; FREITAS, S.F.T. de. Aspectos epidemiológicos da saúde bucal do idoso no Brasil. Cadernos de Saúde Pública, v.18, n.5, p.1313-20, set./out. 2002.

10. ECKERBON, M.; MAGNUSSON, T.; MARTINSSON, T. Reasons for and incidence of tooth mortality in a Swedish population. Endod. dent. Traumat., v.8, n.6, p.230-4, Dec. 1992.

11. EMERY, R.W.; GUTTENBERG, S.A. Manegement priorities and treatment strategies for medical emergencies in the dental office. Dent. Clin. N. Amer., v.43, n.3, p.401-19, July 1999.

12. FERREIRA JÚNIOR, O. Contribuição social do serviço de urgência odontológica da Faculdade de Odontologia de Bauru - sua participação no convênio com o sistema único de saúde. Bauru, 1997. 116p. Dissertação (Mestrado) Faculdade de Odontologia de Bauru, Universidade de São Paulo.

13. FRANCO L.J. Diabetes como causa básica ou associada de morte no Estado de São Paulo, Brazil, 1992. Rev. Saúde públ., v.32, n.3, p.237-45, jun. 1998.

14. FREIRE, M. do C.M. et al. Prevalência de cárie e necessidades de tratamento em escolares de 6 a 12 anos da rede pública de ensino. Rev. Saúde públ., v.33, n.4, p.385-90, 1999.

15. GABRE, P; MARTINSSON, T; GAHNBERG, L. Incidence of, and reasons for, tooth mortality among mentally retarded adults during a 10-year period. Acta odont. scand., v.57, n.1, p.5561, Feb. 1999.

16. GARCIA, A.G. et al. Pell-Gregory classification is unreliable as a predictor of difficult in extracting impacted lower third molars.

Brit. J. oral Maxillofac. Surg., v.38, n.6, p.585-7, Dec. 2000. 
17. GILBERT, G.H. et al. Tooth-specific and person-level predictors of 24-month tooth loss among older adults. Community Dent. oral Epidem., v.27, n.5, p.372-85, Oct. 1999.

18. GODFREY, K. Prophylactic removal of assymptomatic third molars: a review. Aust. dent. J., v.44, n.4, p.233-7, Dec. 1999.

19. GOLDBAUM, M. Epidemiologia e serviços de saúde. Cadernos de Saúde Pública, v.12, p.95-8, 1996. Suplemento 2.

20. GONÇALVES, E.R.; PERES, M.A.; MARCENES, W. Cárie dentária e condições sócio-econômicas: um estudo transversal com jovens de 18 anos de Florianópolis, Santa Catarina, Brasil. Cadernos de Saúde Pública, v.18, n.3, p.699-706, mai./jun. 2002.

21. GREGORI, C. Cirurgia buco-dento-alveolar. São Paulo, Sarvier, 1996.

22. GUIMARÃES, M.M.; MARCOS, B. Perda de dente relacionada a razões clínicas segundo a classe social. Rev. CROMG, v.1, n.2, p.54-61, ago./dez. 1995.

23. GUIMARÃES, M.M.; MARCOS, B. Expectativa de perda de dente em diferentes classes sociais. Rev. CROMG, v.2, n.1, p.16-20, jan./jun. 1996.

24. HADDAD, I. et al. Reasons for extraction of permanent teeth in Jordan. Int. dent. J., v.49, n.6, p.343-6, Dec. 1999.

25. HOUSTON, J.P. et al. Alveolar osteistis: a review of its etiology, prevention, and treatment modalities. Gen. Dent., v.50, n.5, p.457-63, Sept./Oct. 2002.

26. JOWETT, N.I.; CABOT, L.B. Diabetic hypoglycaemia and the dental patients. Brit. dent. J., v.185, n.9, p.439-42, Nov. 1998.

27. KOSTOPOULOU, O. et al. Decisions to remove asymptomatic third molars require rational criteria. Brit. dent. J., v.184, n.11, p.546, June 1998.

28. LAST, J.M. A dictionary of epidemiology. Nova lorque, Oxford University Press, 1988 apud PINTO, V. G. Identificação de 
problemas. In:

Saúde bucal coletiva. 4 ed. São

Paulo, Ed. Santos, 2000. Cap.5, p.139-222.

29. LEAVELL, H.R., CLARK, E.G. Preventive medicine for the doctor in his community. An epidemiological approach. New York, McGraw Hill, 1958 apud GREGORI, C. Cirurgia buco-dentoalveolar. São Paulo, Sarvier, 1996.

30. LEE, A.; McWILLIAMS, M.; JANCHAR, T. Care of the pregnant patient in the dental office. Dent. Clin. N. Amer., v.43, n.3, p.485-94, July 1999.

31. LOPES, W.C.; NASCIMENTO, Z.C.P. Pacientes com distúrbios sistêmicos na clínica odontológica. ROBRAC Revista Odontológica do Brasil Central, v.6, n.18, p.29-34 jun. 1996.

32. MALCON, M.C.; MENEZES, A.M.B.; CHATKIN, M. Prevalência e fatores de risco para tabagismo em adolescentes. Rev. Saúde públ., v.37, n.1, p.1-7, 2003.

33. MALDEN, N.J.; MAIDMENT, Y.G. Lingual nerve injury subsequent to wisdom teeth removal - a 5-year restropective audit from a high street dental pratice. Brit. dent. J., v.193, n.4, p.203-5, Aug. 2002.

34. MARCENES, W.; MURRAY, S. Social deprivation and traumatic dental injuries among 14-year-old schoolchildren en Newham, London. Dental Traumatology, v.17, n.1, p.17-21, Feb. 2001.

35. MARTINS, I.S. et al. Doenças cardiovasculares ateroscleróticas, dislipidemias, hipertensão, obesidade e diabetes melito em população da área metropolitana da região Sudeste do Brasil. III - Hipertensão. Rev. Saúde públ., v.31, n.5, p.466-71, out. 1997.

36. MARZOLA, C. Técnica Exodôntica. 3. ed. São Paulo, Pancast, 2000.

37. McCAUL, L.K.; JENKINS, W.M.M.; KAY, E.J. The reasons for extraction of permanent teeth in Scotland: a 15-year follow-up study. Brit. dent. J., v.190, n.12, p.658-62, June 2001. 
38. MENDONÇA, G.A.S. Tendências da investigação epidemiológica em doenças crônicas. Cadernos de Saúde Pública, v.17, n.3, p.697-703, mai./jun. 2001.

39. MINISTÉRIO DA SAÚDE, SECRETARIA DE POLÍTICAS DE SAÚDE. Plano de Reorganização da Atenção à Hipertensão arterial e ao Diabetes mellitus Manual de Hipertensão arterial e Diabetes mellitus. Brasília, 2002.

40. MOGHADAM, H.G.; CAMINITI, M.F. Life-threatening hemorrhage after extraction of third molars: case report and management protocol. J. Canad. dent. Ass., v.68, n.11, p.670-4, Dec. 2002.

41. MOREIRA, R.W.F. et al. Perfil dos pacientes submetidos a exodontia na Faculdade de Odontologia de Piracicaba UNICAMP. Revista de Odontologia da Universidade de Passo Fundo, v.3, n.2, p.33-9, jul./dez. 1998.

42. MORITA, M. et al. Reasons for extraction of permanent teeth in Japan. Community Dent. oral Epidem., v.22, n.5, p.303-6, 1994.

43. MURRAY, H.; CLARKE, M.; LOCKER, D. Reasons for tooth extration in dental practices in Ontario, Canada according to tooth type. Int. dent. J., v.47, n.1, p.3-8, Feb. 1997.

44. NARVAI, P.C.; CASTELLANOS, R.A.; FRAZÃO, P. Prevalência de cárie em dentes permanentes de escolares do Município de São Paulo, SP, 1970-1996. Rev. Saúde públ., v.34, n.2, p.196-200, 2000.

45. NICHOLLS, C. A 12-year retrospective audit study of tooth loss in a general dental practice. Brit. dent. J., v.189, n.2, p.98-9, July 2000.

46. NOVAES, H.M.D. Epidemiologia e avaliação em serviços de atenção médica: novas tendências na pesquisa. Cadernos de Saúde Públ., v.12, , p.7-12, 1996. Suplemento 2.

47. ONG, G. Periodontal disease and tooth bos. Int. dent. J., v.48, 
n.3, p.233-8, June 1998.

48. ONG, G.; YEO, J.F.; BHOLE, S. A survey of reasons for extraction of permanent teeth in Singapore. Community Dent. oral Epidem., v.24, n.2, p.124-7, Apr. 1996.

49. PADUA, J.M. de et al. Incidência de alveolite seca após exodontia de dentes irrompidos. Rev. Ass. paul. cirurg. Dent., v.56, n.4, p.283-7, jul./ago. 2002.

50. PELL, G.J.; GREGORY, B.T. Impacted mandibular third molars classification and modified techniques for removal. Dent. Digest, v.39, p.330, 1933.

51. PEREIRA, M. G. Epidemiologia, teórica e prática. Rio de Janeiro, Guanabara Koogan, 1995.

52. PERES, M.A. de A.; NARVAI, P.C.; CALVO, M.C.M. Prevalência de cárie dentária em crianças aos doze anos de idade, em localidades do Estado de São Paulo, Brasil, período 1990-1995. Rev. Saúde públ., v.31, n.6, p.594-600, 1997.

53. PETERSON, L.J. et al. Contemporary oral and maxillofacial surgery. 2.ed. St. Louis, Mosby, 1993.

54. PINTO, V.G. Identificação de problemas. In: Saúde bucal coletiva. 4 ed. São Paulo, Santos, 2000. Cap.5, p.139222.

55. REICH, E.; HILLER, K.A. Reasons for tooth extraction in the western states of Germany. Community Dent. oral Epidem., v.21, n.6, p.379-83, 1993.

56. Report of a workshop on the management of patients with third molar teeth. J. oral Maxillofac. Surg., v.52, n.10, p.1102-12, Oct. 1994.

57. ROUQUAYROL, M.Z., 1993. Epidemiologia e Saúde. 4.ed. Rio de Janeiro, Medsi, 1993 apud GOLDBAUM, M. Epidemiologia e serviços de saúde. Cadernos de Saúde Pública, v.12, p.95-8, 1996. Suplemento 2.

58. SAĐLAM, A.A.; TÜZÜM, M.P. Clinical and radiologic investigation 
of the incidence, complications, and suitable removal times for fully impacted teeth in the Turkish population. Quintessence Int., v.34, n.1, p.53-9, Jan. 2002.

59. SALES PERES, S.H. de C.; BASTOS, J.R. de M. Perfil epidemiológico de cárie dentária em crianças de 12 anos de idade, residentes em cidades fluoretadas e não fluoretadas, na Região Centro-Oeste do Estado de São Paulo, Brasil. Cadernos de Saúde Pública, v.18, n.5, p.1281-8, set./out. 2002.

60. SAMAJA, J. Epistemología y metodología: elementos para una teoria de la investigación científica. Buenos Aires, Editorial Universitaria de Buenos Aires, 1993. apud BARATA, R. C. B. O desafio das doenças emergentes e a revalorização da epidemiologia descritiva. Rev. Saúde públ., v.31, n.5, p.531-7, out. 1997.

61. SANT'ANA, E.; FERREIRA JUNIOR, O.; PINZAN, C.R.M. Avaliação da freqüência da posição dos terceiros molares inferiores não irrompidos. $\mathrm{BCl} \mathbf{B C l}$ Revista Brasileira de

Cirurgia Implantodontia., v.7, n.27, p.42-5, jul./ago./set. 2000.

62. SHAMPAINE, G.S. Patient assessment and preventive mesures for medical emergencies in the dental office. Dent. Clin. $\mathbf{N}$. Amer., v.43, n.3, p.383-400, July 1999.

63. SUSSER, M. Casual thinking in the health sciences: concepts and strategies in epidemiology. Nova lorque, Oxford University Press, 1973. apud PINTO, V. G. Identificação de problemas. In: Saúde bucal coletiva. 4 ed. São Paulo, Santos, 2000. Cap.5, p.139-222.

64. TAVARES, B.F.; BÉRIA, J.U.; LIMA, M.S. Prevalência do uso de drogas e desempenho escolar entre adolescentes. Rev. Saúde públ., v.35, n.2, p.150-8, 2001.

65. TOMITA, N.E. et al. Condições periodontais e diabetes mellitus na população nipo-brasileira. Rev. Saúde públ., v.36, n.5, p.607- 
13, 2002.

66. TRAEBERT, J. et al. Prevalência e severidade de cárie dentária e necessidade de tratamento odontológico em pequenos municípios brasileiros. Cadernos de Saúde Pública, v.18, n.3, p.817-821, mai./jun. 2002.

67. TRINDADE I.S. et al. Prevalência da hipertensão arterial sistêmica na população urbana de Passo Fundo (RS). Arquivos Brasileiros de Cardiologia, v.71, n.2, p.127-30, 1998.

68. VASCONCELOS, R.J.H. et al. Incidência dos terceiros molares retidos em relação à classificação de Winter. Revista de Cirurugia e Traumatologia Buco-Maxilo-Facial., v.2, n.1, p. 43-47, jan./jun. 2002.

69. WINTER, G.B. Impacted mandibular third molar. St. Louis, American Medical Book, 1926.

70. WORTHINGTON, H.V.; CLARKSON, J.E.; DAVIES, R.M. Extraction of teeth over 5 years in regulary attending adults. Community Dent. oral Epidem., v.27, n.3, p.187-93 Jun. 1999.

71. YAMAOKA, M.Y. et al. Root resorption of mandibular second molar teeth associated with the presence of the tirad molars. Aust. dent. J., v.44, n.2, p.112-6, June 1999. 
APÊNDICES 


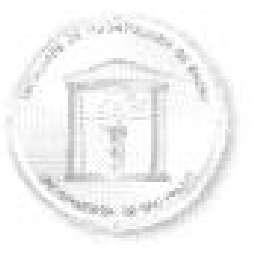

\title{
Universidade de São Paulo Faculdade de Odontologia de Bauru
}

AJ. Dr. Octávio Pinheiro Brisolla, 9-75 - Bauru-SP-CEP 17012-901 - C.P. 73 PABX (0XX14)235-8000 - FAX (0XXI4)223-4679

\author{
Comifê de Ética em Pesquisa
}

Processo $n^{\circ} 017 / 2003$

Bauru, 31 de marco de 2003

Senhora Professora,

O projeto de pesquisa encaminhado a este Comitê de Ética "Perfil epidemiológico dos pacientes atendidos nas clinicas da disciplina de cirurgia da Faculdade de Odontologia de Bauru - USP" de autoria de Cláudio Roberto Gaião Xavier, sob sua orientaçăo foi enviado ao relator para avaliação.

Na reunião de 26 de março, o relator emitiu o seguinte parecer, que foi considerado pelo Comitê: Aprovado com Recomendação.

O referido projeto de pesquisa pode ser aprovado, pois não apresenta nenhum probiema ético em seu protocolo de pesquisa apresentado a esse comitê para apreciaçăo. Contudo. gastariamos de recomendar ao pesquisador e ao mesmo fempo pedir aiguns esclarecimentos em relação ao que se segue abaixa.

a) Recomendaçảo: a confidencialidade dos dados obtidos nos prontuănios, em relaçăo a preservaçảo da identidade do verdadeiro dono do prontuério. Lembramos aqui que a Insthtuiçâo tem apenas a guarda das prontuários, mas não è dona deles. Pois to prontuáno é para uso no cuidado médico, năo para pesquisa' (ctr, 'Cademos de Ética em Pesquisa' $n^{\circ} 03$ pág.11). como julgamos ser muito difial entrar em contato com todas as verdadeiros donos dos prontuánios para obter o consentimento para a utî̉zaçāo de seus dados para a pesquisa em questâo, cremos que podemos autorizar a pesquisa, acentuando, contudo, a responsabilidade do pesquisador, juntamente com este CEP, de serem as guardiazes da infegridade do dono do prontuário.j

b) Esclarecimentos: na página 18 no item Material e Métodos' o pesquisador nos informa o seguinte: 'A análise dos prontuàrios será realizada por apenas um examinador...' (mas nâo fala quem(?) ). Cremos que esse examinador senia o próprio pesquisador e autor do projeto, caso nấo o seja, gostariamos de ser informados quem fania isso.

c) Esclarecimento: na folha de rosto, no titulo Sujeitos da Pesquisa, item 9, o pesquisador nos informou tratar-se de 3927 (trés mil, novecentos e vinte e sete) sujeitos. Gostariamos de saber como o pesquisador chegou a esse numero se o seu projeto de pesquisa näo visa trabalhar com sujeitos e sim com prontuánios?

Cremos que seria interessante o pesquisador esclarecer a esse comité esses pormenores, năo imviabiizzando, contudo, o inicio da pesquisa a partir desta data de aprovaçăo do protocolo de pesquisa junto a este CEP

Atenciosamente,

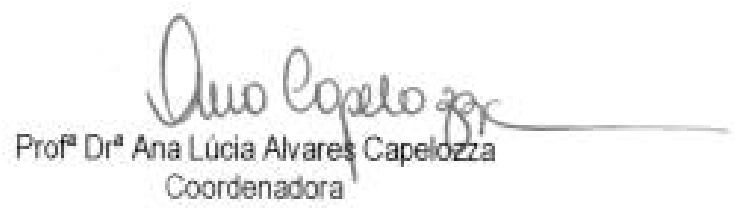

$\| \mathrm{lm}^{0} \mathrm{Sr}$. Prof. Dr. Osny Ferreira Júnior

DD. Docente do Departamento de Estomatologia (Cirurgia) 


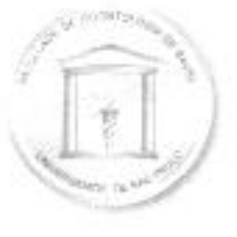

\section{Universidade de São Paulo Faculdade de Odontologia de Bauru \\ Al. Dr. Octávio Pinheiro Brisolla, 9-75-Bauru-SP - CEP 17012-901 - C. P. 73 PABX $(0 \times X 14) 235-8000-\mathrm{FAX}(0 \times X 14) 223-4679$ \\ Comifê de Ética em Pesquitsa}

Processo $n^{\circ} 017 / 2003$

Bauru, 17 de abril de 2003

Senhor Professor,

Informamos que após o envio da documentaçào pendente, o projeto de pesquisa encaminhado a este Comitẽ denominado "Perfil epidemiológico dos pacientes atendidos nas clínicas da disciplina de Cirurgia da Faculdade de Odontologia de Bauru-USP ${ }^{\prime \prime}$ de autoria de Claudio Roberto Gaiào Xavier, que será desenvolvido sob sua orientação, foi APROVADO, nesta data.

Comunicamos que após o envio do trabalho concluido, este Comitê enviará o parecer final, que será utilizado para a publicaçào do trabalho.

Atenciosamente,

Prof Dr Ana Lúcia Alvares Capelozza

Coordenadora

$11 m^{\circ}$ Sr. Prof. Dr. Osny Ferreira Júnior

DD. Docente do Departamento de Estomatologia (Disciplina de Cirurgia) 
ABSTRACT 


\section{Abstract \\ Epidemiological profile of patients examined at Surgery clinics of Bauru School of Dentistry, University of São Paulo}

This study had analyzed files of patients who have been examined at Surgery clinics of Bauru School of Dentistry, University of São Paulo (FOB-USP), between January 1997 and December 2002. Data related to gender, age, living location, kind of proceeding that have been done and the day that it have done, number of extracted teeth, accidents and complications that could have occurred, medical history, blood pressure, local were radiographies had been made and reference to extractions were recorded. The analyses of data made possibly to do the following statements: (1) 3927 patients have been examined during this period; (2) there were more female (61.1\%) than male (38.9\%); (3) $59,2 \%$ of patients were 11 to 30 years old; (4) Bauru was the most benefited city by Surgery clinics of FOBUSP service; (5) $67.39 \%$ of patients have took their radiographies at FOBUSP; (6) teeth extraction were the most executed proceeding; (7) alveolar osteitis was the most frequent complication observed; (8) diabetes and high blood pressure incidence were $2.36 \%$ and $18.53 \%$, respectively; (9) 8471 teeth were extracted, media of 3.59 extracted teeth per patient; (10). It can be concluded that: (1) a conservative philosophy related to teeth extraction reference should be applied, because frequency of patients aged 30 years old or less was 59.9\%; (2) accidents and complications indices are at satisfactory level; (3) primary reference to extraction was non irrupted teeth. 